\title{
Estampación serigráfica: Antecedentes de la serigrafía
}

Angélica Estefanía Romero Magallanes - Universidad Autónoma de Chihuahua (D) 0000-0001-5494-3758

Recepción: 07.05.2021 | Aceptado: 21.06.2021

Correspondencia a través de ORCID: Angélica Estefanía Romero

iD 0000-0001-5494-3758

Citar: Romero Magallanes, AE (2021). Estampación serigráfica: Antecedentes de la serigrafía. REIDOCREA, 10(25), 1-22.

Agradecimiento: Marisa Mancilla Abril, quien me otorgó su apoyo constante durante mi estadía en Granada y fue quien revisó mi trabajo y me otorgó una favorable retroalimentación. Mujer brillante, talentosa y amable a quien admiro profundamente. Gracias por ser una gran inspiración.

Área o categoría del conocimiento: Artes Gráficas

Resumen: El proceso de estampación serigráfica es una técnica artística muy joven comparada con las demás técnicas gráficas, que surge gracias a la aportación de diferentes procedimientos que tienen en común la utilización de una plantilla para generar una estampa, como el estarcido, que tiene orígenes ancestrales, y que evoluciona gracias a la aportación de los procedimientos de diferentes culturas. La serigrafía surge gracias a la aportación de diferentes patentes de creadores que buscaban generar plantillas solucionando el problema de los puentes entre las partes sueltas de la imagen (No era solo estético, era un problema muy serio que comprometía la viabilidad del proceso). En sus comienzos la serigrafía se utilizaba principalmente con fines industriales y publicitarios, pero los artistas descubrieron que podían utilizarla para generar obras con un valor estético, por lo que hubo una constante búsqueda por darle un lugar entre las técnicas gráfica, que se logra gracias al Pop Art, ya que los artistas americanos como Andy Warhol la utilizaron para generar obras que reflejaran su entorno y sociedad, influenciada por los medios de comunicación y el consumismo, dándole un lugar como técnica artística, y abriéndole paso dentro de museos de fama mundial.

Palabra clave: Artes Gráficas

Silkscreen printing: History of the Silkscreen

Abstract: The silkscreen printing process it's a relatively new technique compared to other graphic techniques, which turned relevant thanks to the contribution of different procedures which have in common the use of a stencil to generate a stamp, has ancestral origins, and evolves thanks to the contribution of the procedures of different cultures. Screen printing arises thanks to the contribution of different patents from creators who sought to generate templates by solving the problem of the unions between the loose parts of the image (It was not only not aesthetic, but it was also an annoying problem that compromised the viability of the process). In its beginnings, screen printing was used mainly for industrial and advertising purposes, but the artists discovered they could use it to generate artworks with aesthetic value, and there was a constant effort to give it a place among graphic techniques, which is achieved thanks to Pop Art, with the help of American artists such as Andy Warhol, who used the technique to generate artworks that reflected their context and society, influenced by the media and consumerism, giving it a place as an artistic technique, and making its way into world-famous museums.

Keyword: Graphic Arts

\section{Introducción}

La serigrafía es un proceso de estampación utilizado para la reproducción de imágenes en masa, sobre cualquier tipo de material. Consiste en la transferencia de tinta a través de una malla tensada en un marco. Es un proceso para generar imágenes impresas de manera repetitiva sin perder calidad ni definición.

Este procedimiento surge de un desarrollo constante que evoluciona desde su cruda forma inicial a partir de plantillas o estarcidos, hasta su más reciente encarnación como un sistema para producir sofisticadas obras de arte, abriéndose paso y evolucionando, 
suprimiendo sus propias limitaciones, experimentando técnicas nuevas y modernos materiales, con un gran sentido de manifestación creativa e ilustración de lo estético.

No podemos relacionar una fecha específica con el nacimiento de la serigrafía, porque es una técnica que se fue desarrollando paulatinamente; se puede considerar al estarcido como el antecedente más directo, que surge de diferentes aportaciones de varias culturas en diferentes contextos y diferentes momentos de la historia que fueron conformando lo que hoy conocemos como serigrafía. El establecimiento formal de la serigrafía como una técnica artística es, por tanto, bastante joven en comparación con otras técnicas gráficas.

\section{Origenes: el proceso serigráfico}

\section{1.- Antecedentes}

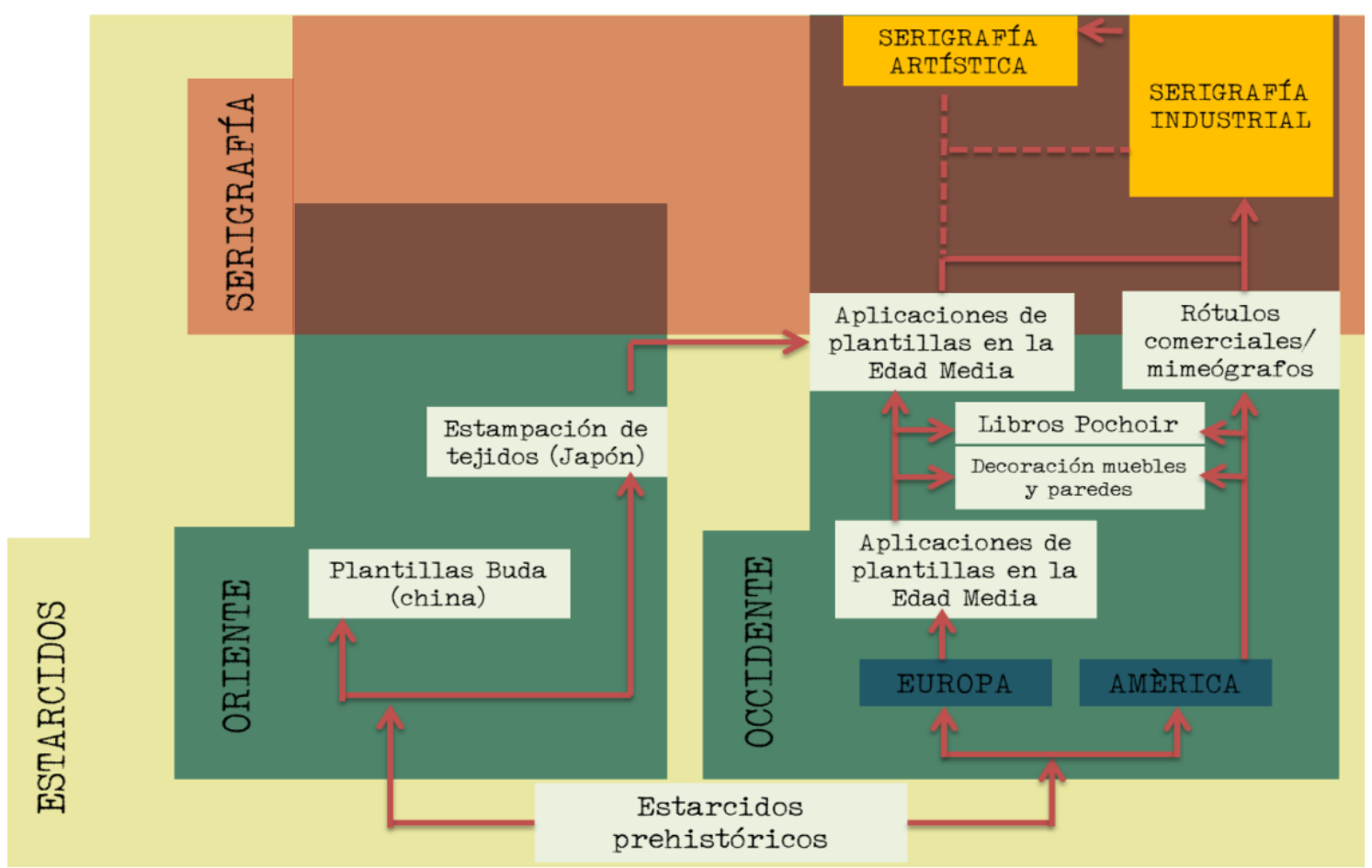

Figura 1: Esquema del proceso evolutivo de la serigrafía

\section{1.- El estarcido}

El estarcido es un recurso de estampación, que se tiene como el antecedente más antiguo de la serigrafía. Se fundamenta en la utilización de plantillas, con las que es posible estampar sobre cualquier tipo de superficie. Representa una enorme ventaja en términos de reproducción masiva de imágenes impresas.

Martínez Vela (2013:32) menciona que:

Tiene un fundamento muy sencillo: Se construye una plantilla sobre una superficie muy rígida, a la cual se le recorta una imagen, dejando huecas las zonas correspondientes, y se procede a colocarla sobre una superficie cualquiera, ya través de ella se hace pasar color mediante instrumentos adecuados para ellos (pinceles, rodillos, spray, esponjas, etc.), y al retirar la plantilla aparecerá la imagen con la forma de los huecos recortados. Quedando registrada la forma sobre la superficie. 


\subsubsection{La antigüedad}

Esta técnica milenaria es sin duda el más antiguo de todos los sistemas de registro de imágenes; podemos encontrar ejemplos de este tipo de procedimiento gracias a las manifestaciones artísticas en las cavernas prehistóricas que fueron dejadas por nuestros antepasados; estas manifestaciones por lo general consistían en la decoración de muros con manos, Martínez Vela (2013:26) comenta que:

La técnica empleada debía consistir en colocar la mano abierta sobre la pared y pulverizar sobre ésta la pintura soplándola directamente con la boca o ayudándose quizás de un junco o caña a modo de tubo o, en otros casos, embadurnando la pared por encima de la mano hasta obtener las imágenes negativas de ellas. Los pigmentos se obtenían directamente de la naturaleza: carbón o magnesio para los negros, óxidos de hierro para los rojos y tierras para los ocres.

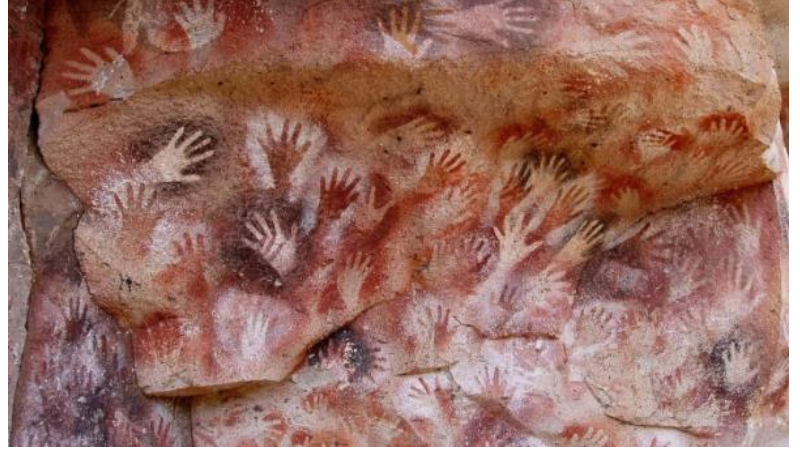

Figura 2: Pinturas de la Cueva de las Manos, Santa Cruz (Argentina)

Nuestros antepasados fueron capaces de percibir su propia capacidad de dejar un registro o huella en su entorno, y algunos autores incluso pueden identificar una especia de intencionalidad artística, como sinónimo de presencia, y registro de una acción. Muñoz del Almo (2013:26) Menciona que «Se trataba de una comparación que incidía en la esencia más básica del acto de grabar: el registro de una presión y un movimiento sobre una superficie. La huella como signo de ubicuidad, sinónimo de presencia, registro de una acción.»

Algunos ejemplos se encuentran plasmados en las paredes de las cavernas de Maltravieso (Figura 3), en los Pirineos, en las Cuevas Magdalenas, y las cuevas de las manos en Argentina (figura 2).

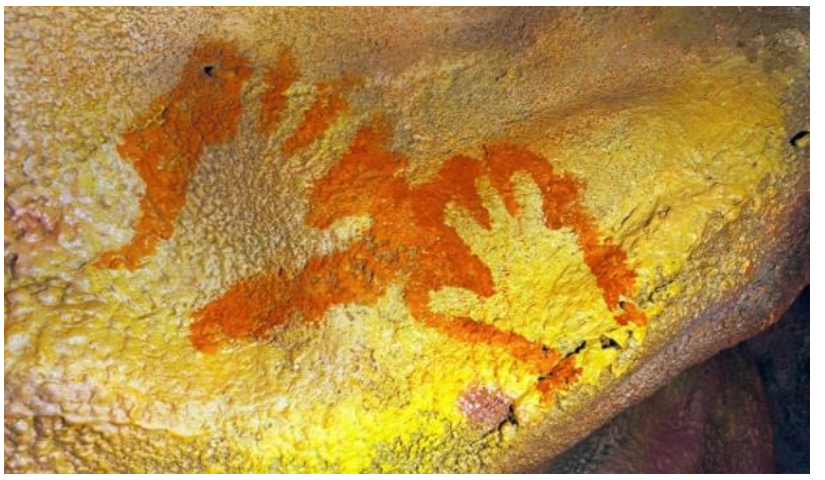

Figura 3: Pinturas de la Cueva de Maltravieso (España)
En el mundo antiguo, las plantillas tuvieron aplicaciones muy diversas; Ross Nielsen (1965:5) comenta que «los egipcios hicieron usos de estarcidos en las pirámides y templos, para decoraciones murales e interiores, y en la ornamentación de la cerámica».

Las plantillas eran utilizadas para el diseño de los contornos de los mosaicos griegos. En la Roma clásica, se utilizaba para la creación de letreros pintados sobre tableros de madera que anunciaban los espectáculos del Coliseo; esto era una forma primitiva de publicidad.

\subsubsection{Oriente}

Las aportaciones del medio oriente en la evolución del uso de plantillas para la estampación son cruciales para su desarrollo. Cossú y Dalquié (2015:10) mencionan 
que: «La primera forma reconocible de serigrafía apareció en China durante la dinastía Song (960 a.C. - 1279 d.C.). Los japoneses de apropiaron de la técnica y la perfeccionaron como disciplina artística.»

Los artesanos japoneses y chinos utilizaron con gran destreza las plantillas para la estampación de tejidos de seda, la cerámica, y las paredes interiores y exteriores de templos.

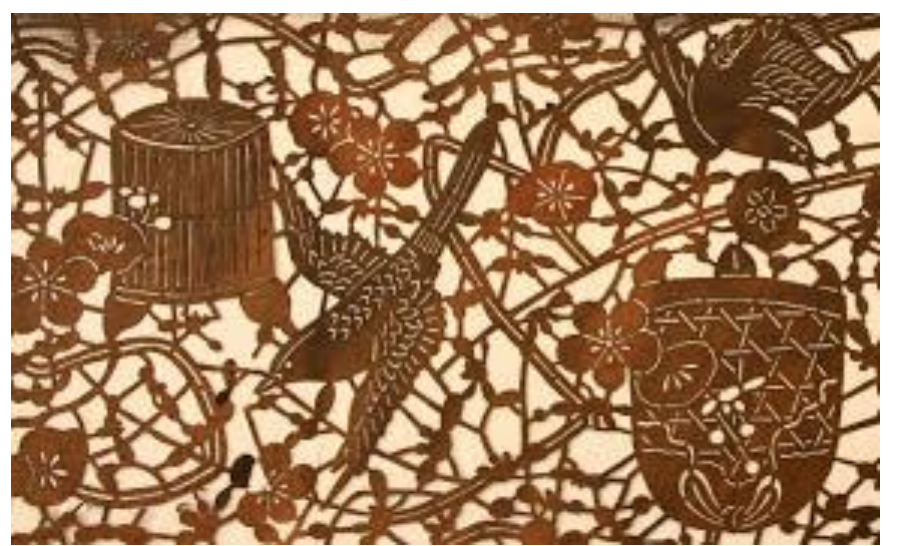

Figura 4: Detalle del Katagami Plum and Nightingale, Siglo XVIII.

Dawson (1982:122) comenta que «Las plantillas de papel de formas complicadas aparecieron en Japón en el siglo XVIII.» Al principio las plantillas eran finas y delicadas, pero con el inconveniente de los puentes o uniones necesarios para mantener unidas las partes sueltas que dividían las plantillas. Con el tiempo, perfeccionan su técnica añadiendo finos hilos de seda o cabellos humanos, creando una especie de plantilla que se conoce con el nombre de katagami (figura 4), utilizada para teñir telas que por lo general eran de algodón, seda, u otras fibras para realizar kimonos, y otras prendas japonesas.

Estas plantillas se realizaban con capas de papel tradicional japonés hecho a mano (conocido como washi), un tipo de papel muy fino que no dejaba huella alguna de su utilización en las estampaciones, engomados con un barniz llamado shibu. Se realizan diseños tallados de patrones producidos por artesanos altamente capacitados, y que eran una muestra de la riqueza y el interés del diseño japonés, así como la notable destreza de las técnicas japonesas de corte. Muchos consideran que este método usado por los artesanos japoneses es el precursor más directo de la serigrafía actual.

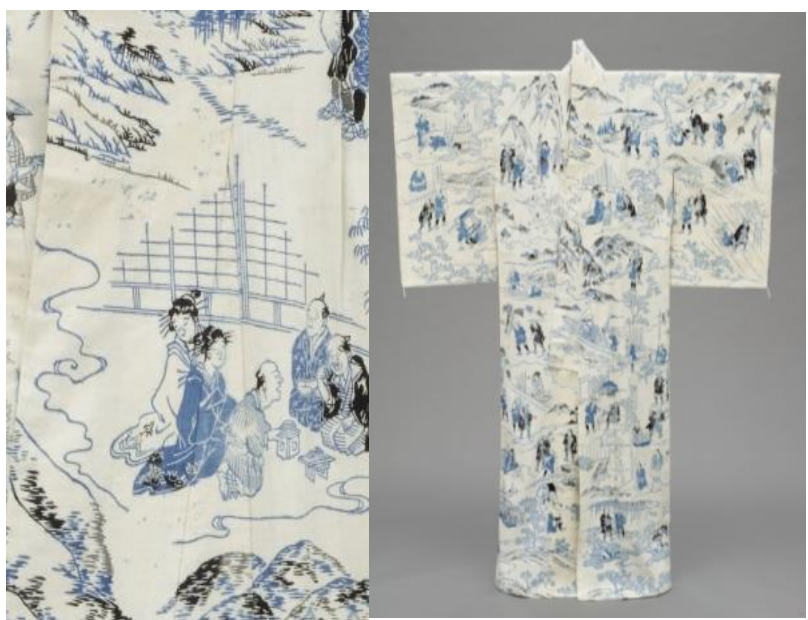

Figura 5: Kimono con estampado Katazome, completo y un detalle a la izquierda. Siglo XIX.

Utilizando la plantilla del katagami, era posible que los artesanos japoneses obtuvieran otro tipo de resultado, conocido como Katazome (figura 5), que es una técnica tradicional japonesa de estampación, que funciona como un método de reserva al imprimir con un engrudo o pasta llamada nori, hecha a partir de harina y salvado de arroz, que se aplicaba sobre la plantilla y se dejaba secar, se introducía el tejido en una tina con tinte, o se pintaba directamente sobre las partes sin la pasta, una técnica utilizada en los tejidos para kimonos. La serigrafía es considerada heredera de esta técnica de estampación japonesa. 
Otra técnica utilizada era la del Surihaku (figura 6), que consistía en aplicar una pasta adhesiva que se aplica con las plantillas katagami, y se presiona sobre ella pan de oro o de plata cuando se encuentra aún húmeda, las técnicas utilizadas eran excelentes mostrando igualmente el solemne trabajo manual oriental. Martínez Vela (2013:33), menciona que «Los kimonos Nob del periodo Edo (1603-1868) son espléndidos ejemplos de la aplicación del estarcido para la decoración de tejidos mediante el método denominado Surihaku.»

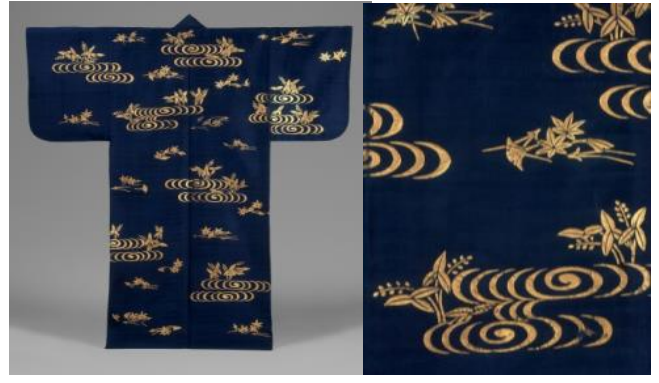

Figura 6: Kimono Nob japonés, del periodo Edo, siglo XIX - Pan de oro sobre seda,
Entre los años 500 y 1000 d.C. La expansión del budismo por el Extremo Oriente estimulo la reproducción masiva de la imagen de Buda y provocó un auge del arte de la fabricación de plantillas que se realizaban sobre un papel al que se le trazaba la figura de buda, y se les hacía pasar algún instrumento afilado y pequeño con el que se hacían puntos muy cercanos entre ellos siguiendo el contorno de la figura, Martínez Vela (2013:34) nos explica el método:

en primer lugar, se dibuja el contorno del buda, luego se doblaba por la mitad, siguiendo el trazado, se pincha el papel a través de ambas caras creando una línea de orificios hasta conseguir dejar el contorno del dibujo marcado a ambos lados, la imagen inicial y una imagen simétrica en el lado izquierdo. Con posteridad la hoja se colocaba sobre el muro y se hacía pasar polvo coloreado a través de los orificios para dejar su huella sobre la pared, un contorno de puntos que servía de guía para el pintor. Este procedimiento permitía la repetición ilimitada del mismo motivo con total exactitud.

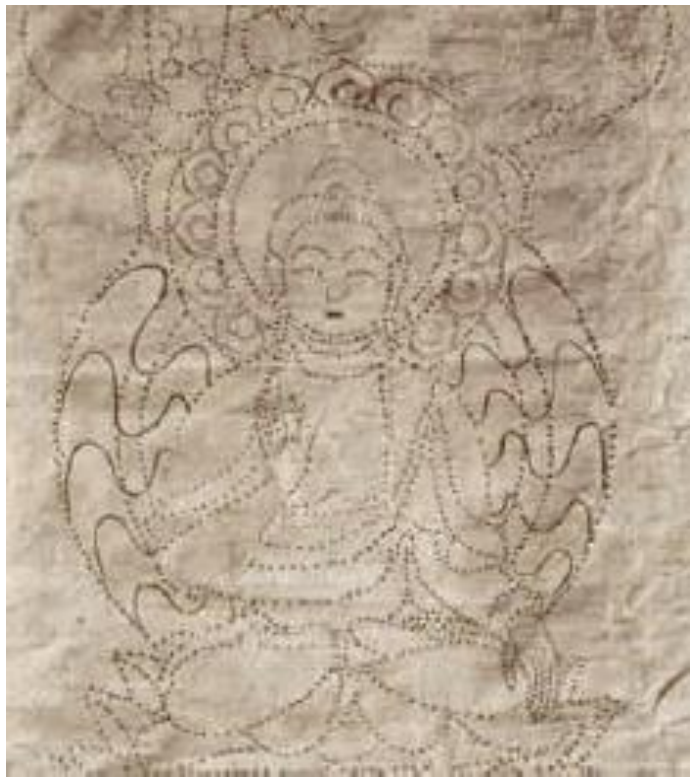

Figura 7: Plantilla de papel perforado de Buda, conservada en el British Museum.

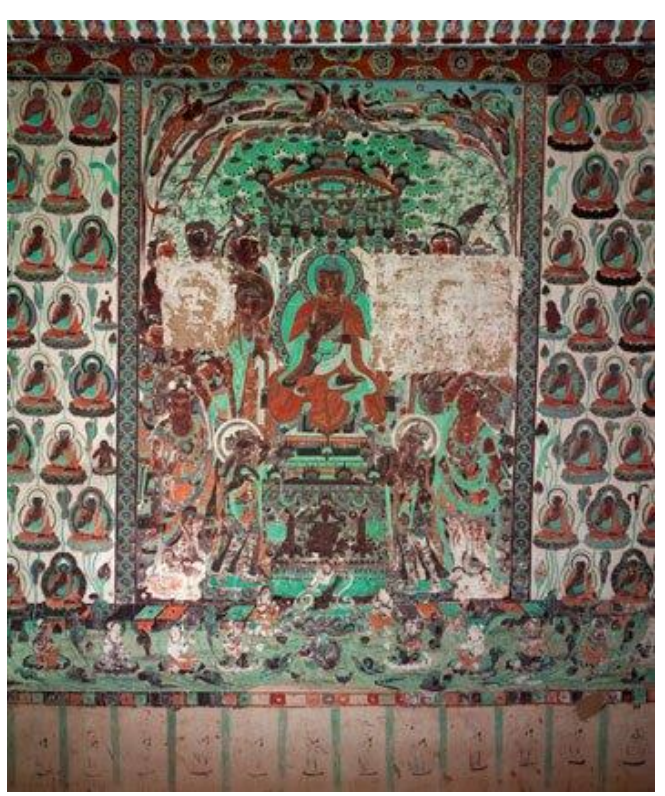

Figura 8: Pintura de Buda de las cuevas de Mogao. 
Este tipo de plantilla fue utilizada para la creación de los murales en los templos de las Cuevas de Mogao, también conocidas como las Cuevas de los mil Budas, en las que se encontró una plantilla con la imagen de Buda (figura 7), y con la cual se realizaron varias de las pinturas de los murales.

\subsection{3.- Europa y EE.UU.}

Martínez Vela (2013:30) menciona que «Los procesos de estampación a través del estarcido se introdujeron en Europa occidental desde China por Marco Polo, entre finales del siglo XIII y principios del XIV.» El avance obtenido en el medio oriente no fue alcanzado al mismo tiempo por Europa, que descubrió de manera tardía estos procedimientos de estampación, incluso los procedimientos eran más toscos.
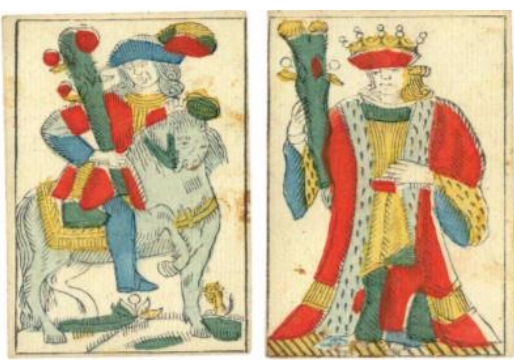

Figura 9: Naipes fabricados en la Real Fábrica de Macharaviaya (Málaga) de 1800

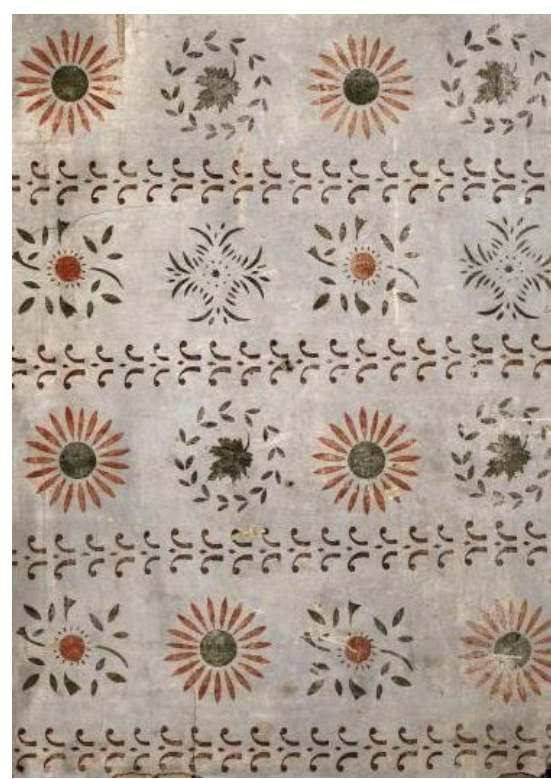

Figura 10: Sección de pared decorada con estarcido de Moses Eaton.

Por tal motivo la Edad Media fue testigo de la utilización de procesos muy rústicos para la estampación de motivos sencillos en los que se utilizaban plantillas en negativo, que se realizaban haciendo un impermeabilizado con alquitrán sobre tejidos de crin tensados, y se procedía a utilizar brochas de pelo duro para hacer pasar la pintura.

Martínez Vela (2013:34) menciona que «También a partir de esta época está datado el uso de plantillas o trepas para colorear a mano estampas religiosas y profanas, y naipes impresos con tacos de madera.»

Durante los siglos XVII y XVIII cobró una gran importancia la utilización de papeles estampados para decorar paredes, muebles, biombos, cortinas, tejidos y variados elementos de hogar, que se estampaba utilizando el método del estarcido a través de plantillas, utilizando una especie de polvillo fino de lana, que daba la impresión de motivos de telas suntuosas.

Section of Stenciled

Para la utilización de fines decorativos, que pulcritud, se empezó a consistía en imprimir muy poco práctico laborioso.

Martínez

Vela

La patente más con una solución Lowenson en

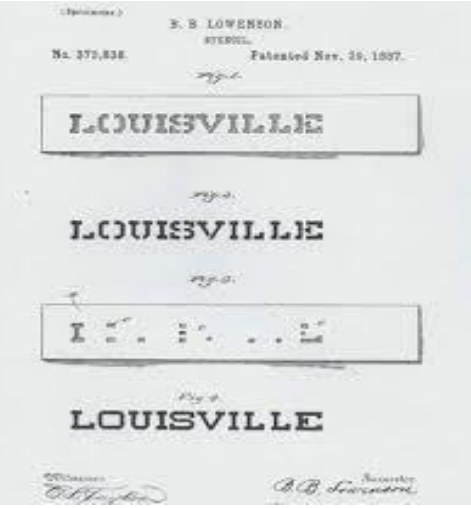

Figura 11: Stencil. Patente de Bernard B. Lowenson (1887)

\section{Plaster Wall and Lating}

plantillas en la rotulación con exigían una mayor estética y utilizar plantillas dobles; esto por partes cada letra, pero era porque era demasiado

(2013:37) menciona que:

antigua que he podido encontrar es la que registró Bernand Ben 1887. Consistía en dos plantillas 
complementarias, una normal y una segunda para ocultar las marcas en blanco dejadas por los puentes.

Este mismo autor nos comenta de otras aportaciones de diferentes personas para resolver el problema que existía con la separación entre plantillas. Aparecen las aportaciones de otros personajes que son bastante ingeniosas, por ejemplo, está David W. Ream, que en el año de 1880 da su aportación a través de una plantilla que funciona con finos hilos metálicos en las partes sueltas, que dejaba una marca más fácil de corregir en la estampación. Martínez Vela (2013:40) nos menciona otras aportaciones importantes para el desarrollo de la serigrafía que se resumen a continuación:

a. Benjamin Walker, que en 1884 registra su patente para hacer plantillas en las que las partes flotantes quedaban sujetas a una rejilla metálica, muy parecido al proceso del Katagami de los artesanos japoneses.

b. William John Miller patenta en 1885 un sencillo sistema de sujeción mediante gruesos alambres doblados.

c. Benjamin Baugh registra en 1890 un método que consiste en sostener las partes flotantes interiores de letras, mediante puentes elevados soldados a la estructura metálica de la plantilla.

Estos tres ejemplos son un reflejo del interés mostrado por solucionar de un modo práctico el problema de los puentes, en la búsqueda de un método de permitiera obtener resultados de más calidad.

\subsection{4.- El pochoir}

El Pochoir es una técnica de estampación altamente refinada para hacer ediciones limitadas finas de estampación. Fue desarrollado en Europa y Estados Unidos a finales del siglo XIX y principios del siglo $\mathrm{XX}$. Se caracteriza por el enorme trabajo manual que requiere, que le otorga un gran valor técnico, pero que es inconveniente como medio de estampación, por el tiempo y trabajo invertido en cada obra.

Fue muy utilizado principalmente para la edición y reproducción de pinturas al óleo y a la acuarela procurando conservar la mayor

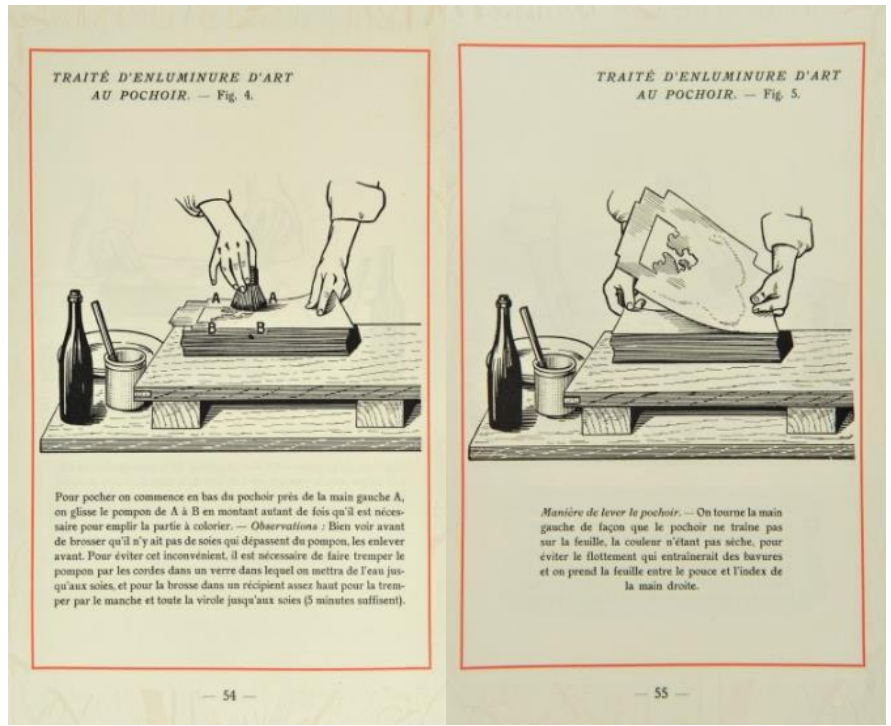

Figura 12: llustraciones de Jean Saudé en Traté d'enluminure d'art au pochoir (1925) cantidad de detalle de la obra.

Fue muy popular en Francia, teniendo su centro de actividad en París, donde fue utilizado principalmente para la ilustración de libros y la estampación de pequeñas piezas de tejidos. Martínez Vela (2013:45) menciona que:

El uso del pochoir para colorear se extendió hasta bien entrado el siglo XX, incluso llegando a mecanizarse con el uso de máquinas que coloreaban con pinceles automáticamente. El pochoir no ha dejado de usarse, pero tras la expansión de la serigrafía pierde relevancia como medio de reproducción. 


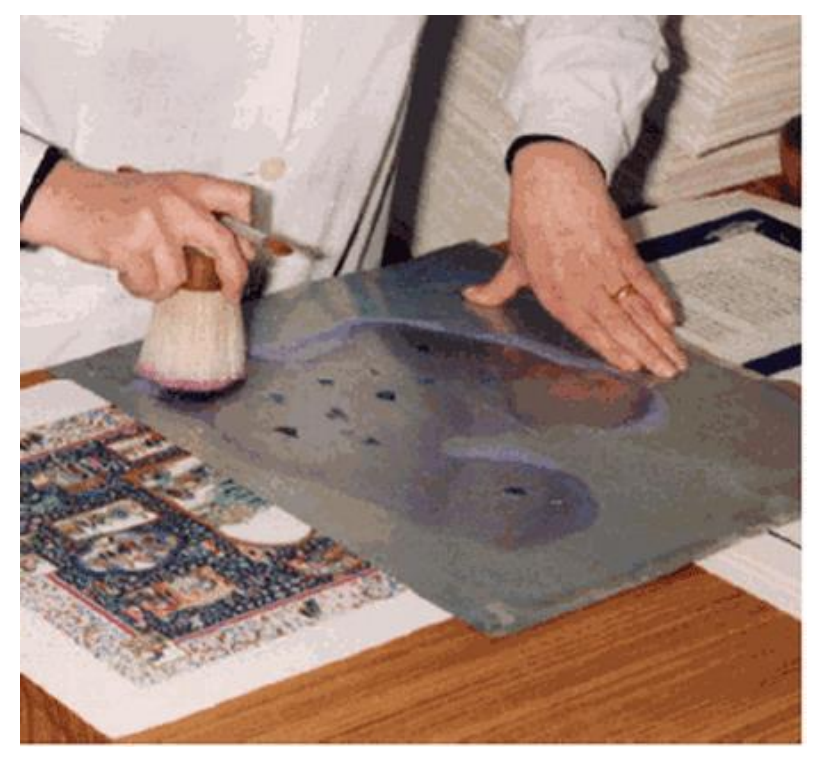

Figura 13: Procedimiento del pochoir.

El procedimiento del pochoir se fundamenta en el análisis de la composición de la obra a reproducir, por tonos y densidades de color, del cual se procede a generar plantillas con un material rígido resistente para cada color, que se colocan en orden encima del soporte elegido para proceder a aplicar el pigmento, teniendo la posibilidad de utilizar una amplia gama de pinceles y métodos para aplicar pintura que propician generar obras con un vasto abanico de posibilidades.

Cada pochoir generado, incluso de una misma plantilla, era único porque el proceso para generar cada estampa es manual, los materiales utilizados daban la posibilidad de obtener diferentes resultados y texturas variando la técnica de aplicación del pigmento (cepillando, pulverizando, salpicando, aplicando con una esponja, etc.). Las obras generadas se caracterizan por ser vívidas tanto en el sentido táctil como el visual, con colores precisos. El pochoir era utilizado tanto para la reproducción de obras de artistas, como para generar obras únicas, y en ambos casos, un pochoir vale por sí mismo como una pieza de arte única.

Se concluye que la serigrafía es una derivación del pochoir, con el cual tiene un fundamento técnico similar, pero enriquecido con la aportación de una enorme cantidad de contribuciones, renunciando a la laboriosidad técnica y la unicidad del pochoir para llegar a lo que conocemos ahora como serigrafía, un proceso eficaz que es capaz de estampar la misma imagen de manera ilimitada obteniendo siempre el mismo resultado.

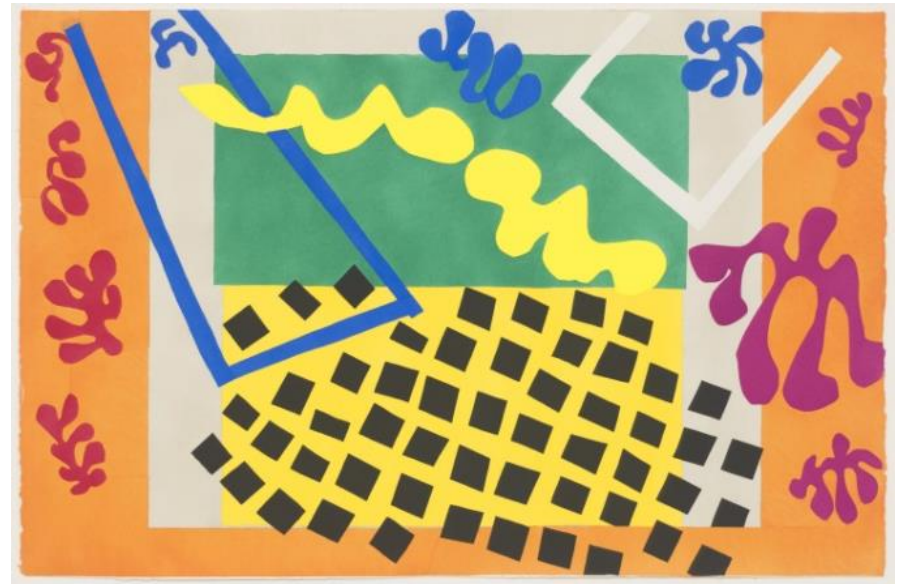

Figura 14: Les Codomas (1947). Uno de los pochoirs incluidos en Jazz, libro de edición limitado de Henir matisse.

\section{2.- Los Mimeógrafos}

A finales del siglo XIX aparece un moderno procedimiento que es también un antecedente de la serigrafía, conocido como el mimeógrafo o Stencil Duplicating Machines. Estos objetos novedosos eran máquinas que duplicaban textos o grabados, que funcionaban al pasar tinta a través de una plantilla sobre un tipo de papel especial, al que se le hacían incisiones con un cilindro metálico. 


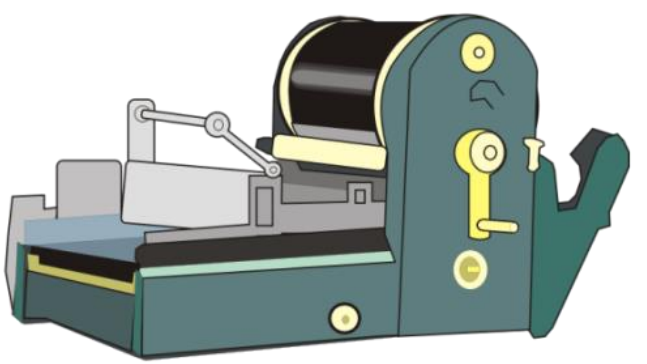

Figura 15: llustración de una máquina mimeográfica típica
Martínez Vela (2013:51) Nos comenta que "casi nadie relaciona los mimeógrafos con la serigrafía, porque son procedimientos que evolucionaron por caminos distintos". Los primeros mimeógrafos comparten muchas características en común con la serigrafía, pero estos en realidad se usan para la impresión en masa de documentos de oficina que suelen ser con un diseño muy sencillo, basado en letras y dibujos de carácter lineal, por lo que en cierto punto empiezan a ser utilizados para otro tipos de impresiones de procedimientos y utilidades muy distintas,

(por ejemplo la reprografía, de la que Crespo [1986:45] comenta que es un «procedimiento electrostático o electrofotográfico que permite la copia múltiple; en la actualidad este conecto aplica a todas las técnicas aptas para la duplicación de documento gráficos.»).

Es importante hacer una mención a la importancia de la contribución de diferentes patentes y creaciones de mimeógrafos al desarrollo de la serigrafía dentro de este panorama. Martínez Vela (2013:53-62) hace una mención de todas las maquinas mimeográficas que fueron patentadas durante esta época, y que tuvieron una importancia significativa para el desarrollo de la serigrafía:

a.- El papyrograph es un sistema patentado por Eugenio Zuccato en 1874, que se utilizaba para realizar duplicados a través de una plantilla generada en papel encerado realizándole agujeros por donde pasaba la tinta.

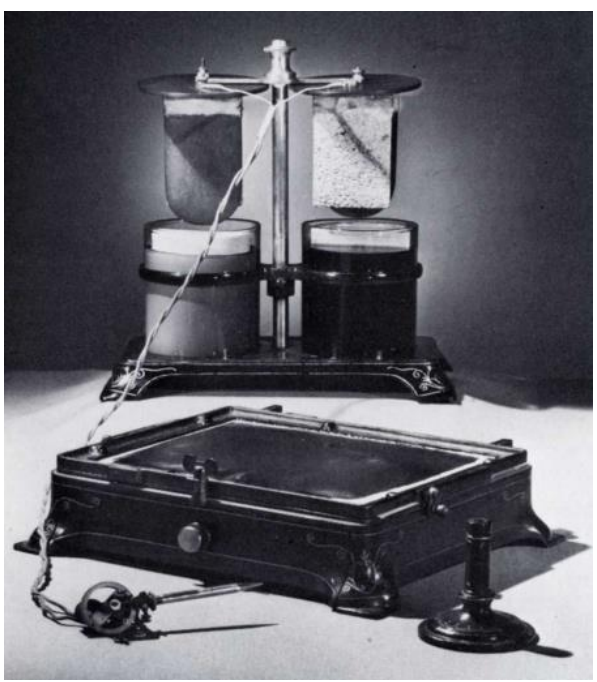

Figura 17: Conjunto completo para la creación de plantillas con el Stencil-pen

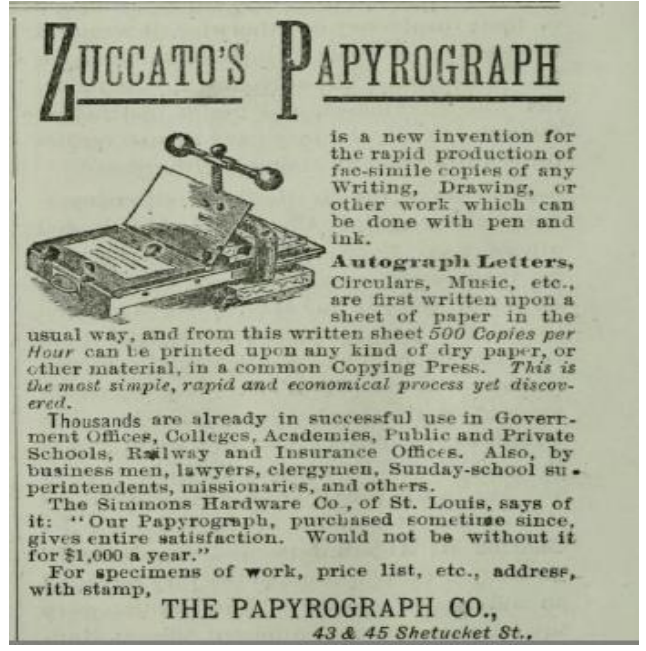

Figura 16: Anuncio del Papyrograph de Euqenio Zuccato

El invento de Zuccato es una máquina para generar plantillas que se fundamenta escribir sobre un papel barnizado con tinta cáustica, que va disolviendo el papel cada vez que se escribe, dejando agujeros en estas zonas. La hoja entonces se convierte en una plantilla que se coloca sobre una hoja en blanco y se le hace pasar tinta con un rodillo para generar un duplicado de ella.

b.- El Stencil-Pen es un aparato creado por Thomas Edison, que funcionaba a través de un pequeño motor que funcionaba con baterías, y que con una aguja realizaba hasta 120 perforaciones por segundo creando la plantilla, a la que se le pasaba un rodillo para que pasara la tinta y crear la impresión. 
Este aparato se conformaba de un equipo para generar plantillas, que se conformaba de la pluma, una batería eléctrica, una prensa de duplicación plana y un rodillo de tinta. Fue el primer aparato para oficina dotado de un motor eléctrico, al escribir se accionaba una aguja de vaivén que generaba hasta 120 perforaciones por segundo, y se utilizaba para escribir o dibujar formas simples; una vez preparado un patrón sobre el papel, se colocaba en la prensa de duplicación plana con una hoja de papel en blanco por debajo, se pasaba el rodillo entintado, y se dejaba una impresión de la imagen en el papel. Este aparato se considera el antecedente de las máquinas para tatuar eléctricas.

C.- El perforating instrumet for producing stencils es un aparato patentado por David Gestetner en 1882, era una especie de pluma con una rueda de acero minúscula con un borde dentado, y que se pasaba a través de una plantilla de cera y la perforaba.

Gestetner fue desarrollando su patente con el tiempo, y fue cambiándole el nombre hasta crear el cyclostyle, el cual patenta en 1891. Este aparato fue de las primeras máquinas rotativas, que retenía en papel y lo hacía pasar de un lado a otro bajo rodillos entintados, generando

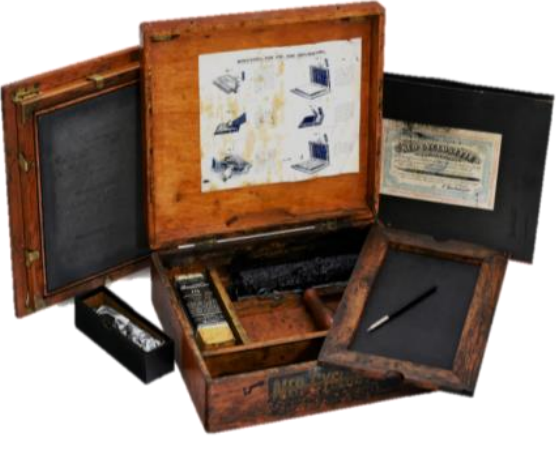

Figura 18: Neo-Cyclostyle de David Gestetner (1822) reproducciones más rápidas y automatizadas; la plantilla se generaba cortando un papel esmaltado utilizando un objeto parecido a un bolígrafo con un pequeño riel en su punta, que perfora la hoja eliminando el esmalte con la punta dentada, luego se hace pasar por un rodillo entintado, estampando en el papel colocado debajo de la plantilla.

d.- En 1884 Albert Blake Dick adquirió las patentes de los sistemas de impresión de Edison, y en 1887 comenzó a comercializar los equipos para hacer copias bajos el nombre de Edison Mimeograph, que generaba plantillas con matrices que se grababa con un lápiz de acero, se colocaba en un marco de impresión, se cerraba con una bisagra y se le aplicaba tinta con un rodillo.
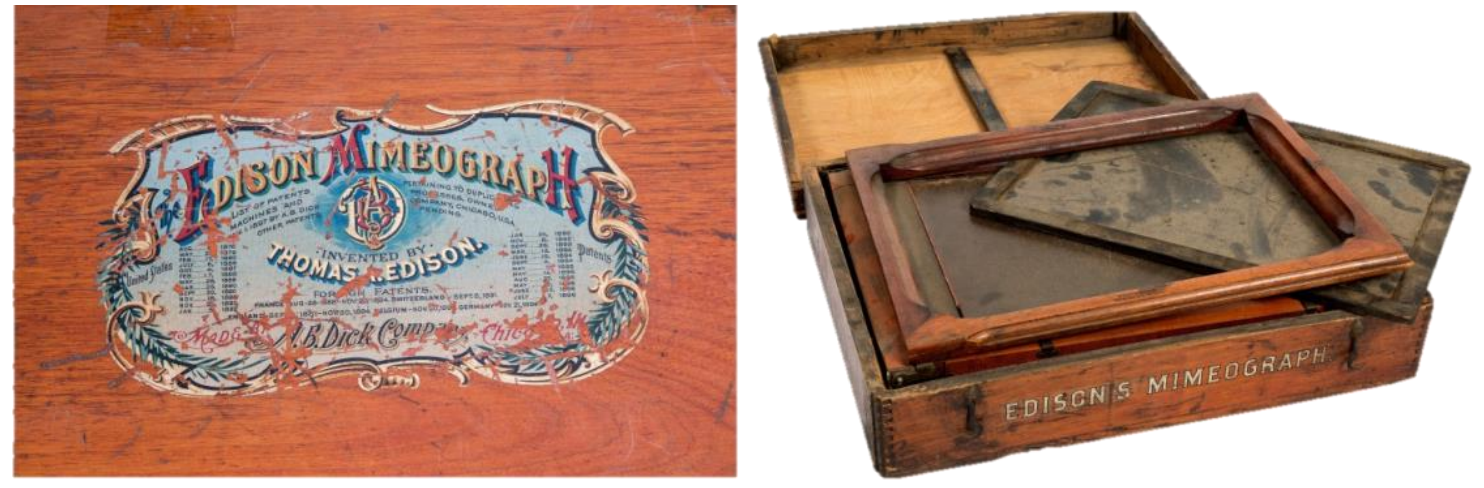

Figura 19: Mimeógrafo de Edison. A la izquierda, portada. A la derecha, mimeógrafo abierto

El aparato, que tuvo mucho éxito, se conformaba de una caja de madera con bisagras que llevaba dentro un marco de impresión (sin pantalla), una placa de tinta, un rodillo de tinta, un tubo de tinta y un tubo de papel encerado. El proceso consistía en colocar una hoja de papel encerado sobre la placa de acero finamente ranurada, en la que se escribía con un lápiz de acero de punta lisa; la plantilla se perforará desde el lado inferior con agujeros diminutos, tan cerca el uno del otro que las fibras de papel que se dividen 
apenas son perceptibles. Esta plantilla se colocaba sobre el marco, y se procedía a entintar con el rodillo sobre una hoja de papel en blanco, generando una copia de este.

e.- Charles $\mathrm{N}$. Jones patenta en 1887 un marco de madera en el que coloca un tejido estirado de seda o lino; es la primera vez que aparece la pantalla que luego será característica del proceso serigráfico.

f.- El frame for Duplicating Apparatus, de Elías S. Walker, es una mesa sobre la que se sujeta un marco y un mecanismo con polea y pedal que levanta y baja el marco, que recuerda mucho a la prensa manual de serigrafía

g.- Aproximadamente en 1900 aparecen las primeras prensas automáticas con auto entintado, como la Automatic Neostyle.

Todos estos procedimientos tuvieron una gran importancia, ya que en cada uno de ellos podemos ver la búsqueda realizada para la mejora en la producción de las plantillas, para que hubiera una mejora en todos aquellos aspectos que antes resultaban tan molestos a la hora de estampar, como las separaciones por puentes. Además, de mano de los cambios y novedades del siglo XX, había una intencionalidad común en cada uno de estos aparatos para convertirlos en un mecanismo de impresión masificado, es decir, capaz de reducir el tiempo en la realización de la plantilla, ahorrando la laboriosidad que conllevaba realizarlas, aumentando y automatizando la cantidad de impresiones obtenidas de una sola plantilla, de acuerdo con las necesidades de esta época.

\section{3.- Nacimiento y difusión de la técnica serigráfica}

\subsubsection{Patentes préserigráficas}

Como bien describe Martínez Vela (2013:64-66) en su libro, son muchos los aparatos y mecanismos que tienen un parecido sustancial con el proceso serigráfico, muchos de ellos son los mencionados anteriormente en el apartado de los mimeógrafos, incluso menciona otros ejemplos citados a continuación:

- Charles Bordas patenta en 1837 un aparato en el que la plantilla queda tensado mediante un sistema de abrazaderas y muelles en un marco de madera que coloca sobre la superficie a imprimir unido por bisagras.

- J. Duff McDonald es el creador del Apparatus For printing Patterns, que es un sistema de poleas y contrapeso que permite levantar la plantilla puesta en un marco de madera mediante listones y tornillos, y de esta manera es posible sacar los trozos de tela a estampar.

Pero, también menciona que, en varios libros se suele dar el reconocimiento a Samuel Simon por crear la primera patente sobre un proceso serigráfico.

Por ejemplo, Ross Nielsen (1965:8) comenta en su libro:

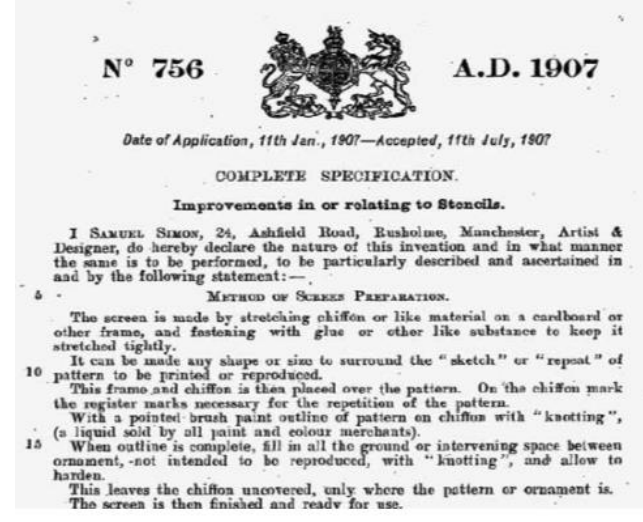

Figura 20: Cédula de Patente de Samuel Simon. 1907 
un estarcido sin puentes naciendo entonces un procedimiento que se llamó, indistintamente, tamiz, trama, pantalla de seda, pochoir de seda, planografía, etc., y se designó por último como serigrafía (del latín sericum, seda, y del griego Graphé: acción de escribir, describir, dibujar).

De igual manera, Cossú y Dalquié (2015:10) comentan en su libro:

La primera patente de la técnica serigráfica - usando seda como plantilla - se concedió en 1907 a Samuel Simon, un rotulista de Manchester. Simon perfeccionó el bastidor de madera con seda tensada e ideó una emulsión para impregnar las zonas de tela que se querían reservar de la tinta que se aplicaba a continuación con una brocha. Esta técnica permitió imprimir rótulos en serie, y no tardó en convertirse en un método habitual para estampar motivos sobre lino, seda y otros tejidos.

Pero Martínez Vela (2013:68) explica en su libro sobre la patente que:

Su invento consistía realmente en un marco de madera o cartón sobre el que tensaba una gasa o malla, y sobre ella pintaba, en negativo, la plantilla con "knotting", consiguiendo de este modo obturar ciertas zonas de la tela dejar abiertas solo las correspondientes a la imagen a reproducir... por lo tanto vemos que Simon no usa plantillas o patrones recortados si no que el clisado de la pantalla lo efectúa mediante bloqueos con un barniz especial llamado Knotting.

\subsection{2.- Raymond y Schreurs}

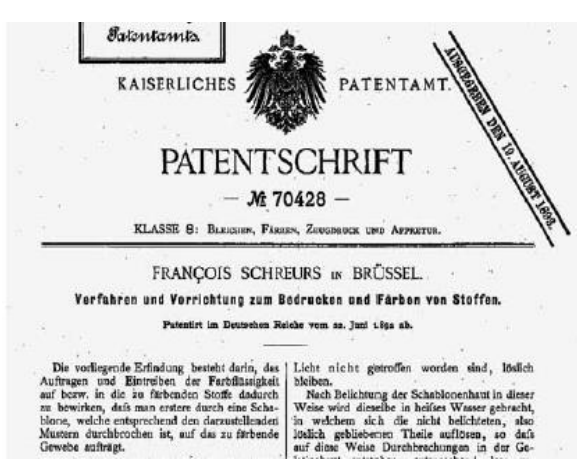

Figura 21: Cédula de Patente de François Schreus (1893).
En conclusión, aunque en la mayoría de los libros sobre serigrafía se suele dar el reconocimiento de la primera patente de un proceso serigráfico a Samuel Simon, existen antes que él otros inventores, Martínez vela (2013:70) nos comenta que hay dos inventores, que realizaron patentes sobre procedimientos que son mucho más parecidos a lo que hoy entendemos por serigrafía; estos personajes son Johan Raymond, y François Schreurs.

- La patente de Schreurs (1906) consiste en un método para impresión utilizando una plantilla hecha con un tul embadurnado de gelatina con dicromato potásico, ésta se expone a la luz que atraviesa un dibujo hecho en un soporte transparente; entonces las partes expuestas a la luz se endurecen y las que son tapadas por el dibujo se disuelven. Menciona textualmente que «es la primera vez que se hace referencia a in proceso fotográfico para el clisado de una pantalla»

- La patente de Raymond se llama Improvements in and relation to stencil (2893); es un procedimiento para obtener plantillas sin separaciones que se realiza en un marco (ya sea de madera, metal u otro material parecido), y una malla de algodón o seda, sobre la cual se realiza proceso fotográfico con bicromato potásico expuesto a la luz con un cristal sobre el que se pinta la imagen, y estas partes en las que no pasa la luz, quedan libres para que pase la tinta. 


\section{4.- Estados Unidos y la serigrafía}

La expansión de la serigrafía como un medio de producción en masa industrial y comercializado se extiende en gran medida durante la primera década del siglo XX en los Estados Unidos; comienza una evolución inminente e interminable, con la que se empiezan a realizar nuevas búsquedas expresivas y se eliminan las limitaciones de la técnica, utilizándola en favor de la obra, y experimentado con nuevos materiales y soportes con los que no era posible trabajar otras técnicas artísticas.

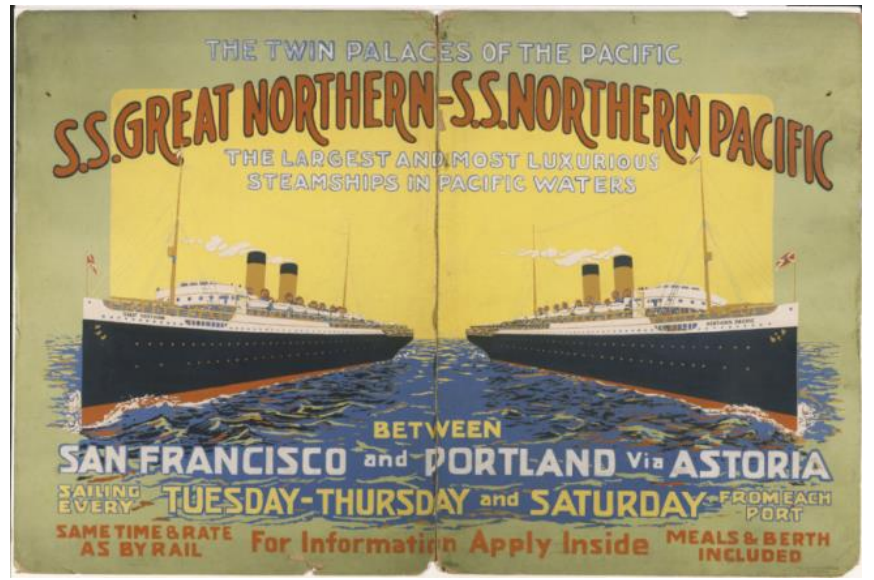

Figura 22: Cartel de la compañía naviera S.S. Great Northen. Conservado en el Philadelphia Museum ofArt. (1916)
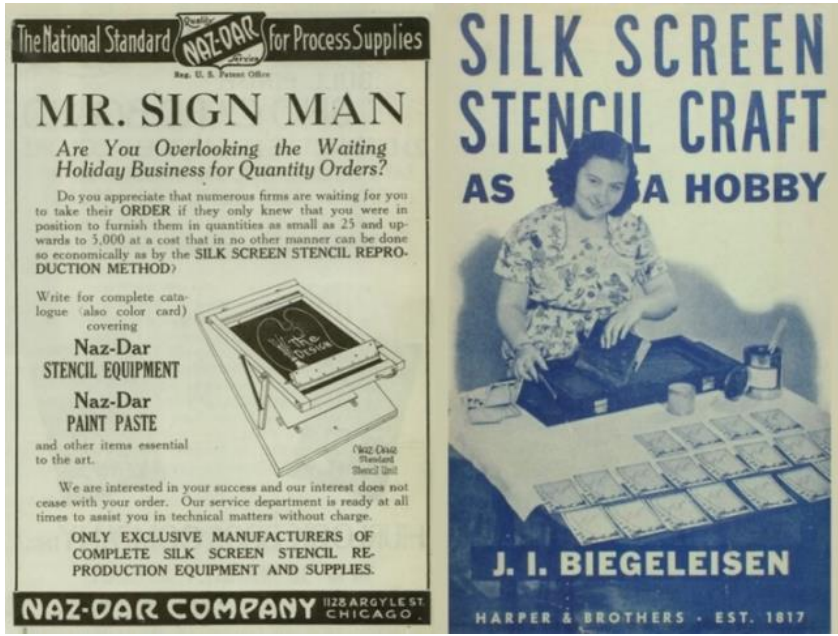

Figura 23: En el periódico Signs of the Times, Nazdar

(Chicago) anuncia los primeros kits de serigrafía en 1925
Durante la época de la Primera Guerra Mundial, el ejército de los Estados Unidos es capaz de vislumbrar los enormes beneficios que conllevaba utilizar la serigrafía, como la facilidad que tenía para la reproducción en masa de diferentes elementos de carácter publicitario (carteles, banderas, emblemas, pancartas, etc.) con fines políticos y laborales.

En estos momentos, los materiales para serigrafía eran muy pocos, de hecho, aún no se habían fabricado tintas específicas para la serigrafía, por lo que, los primeros serígrafos solían utilizar pinturas de aceite para

las impresiones, que no eran muy adecuadas debido a su largo tiempo de secado y a que dejaban contornos grasosos por el aceite que contenían.

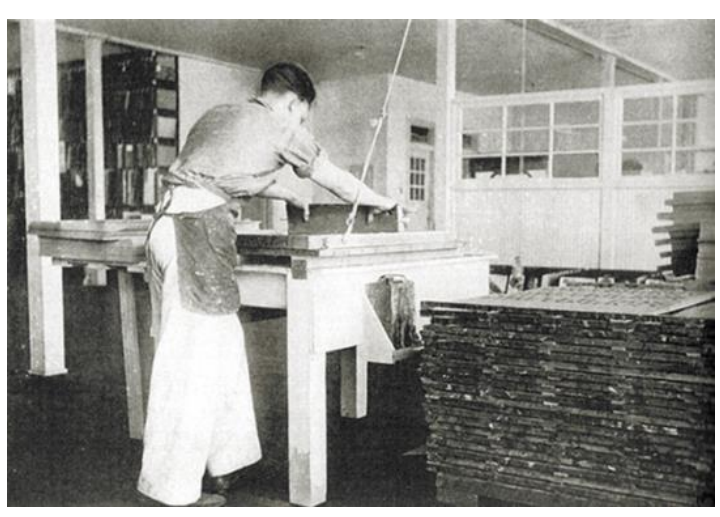

Figura 24: Edwards Owen en la Imprenta Selectasine en 1916-1918
Martínez Vela (2013:86) Comenta que «durante estos primeros años aparece la primera casa suministradora de productos serigráficos, -The Naz-Dar Company creada en Chicago en 1922, y se inicia la difusión del proceso serigráfico con la publicación en 1916 de uno de los primeros artículos sobre el proceso en la revista The signs of the times.»

La empresa Selectasine fue fundada por Roy Beck, Charles Peter y Edward Owner en 1915, que toman como punto de partida la patente de John Pilsworth, quien propone la posibilidad de crear impresiones multicolor de una manera más rápida y económica, con un método de 
estampación de varios colores con una sola maya; Pilsworth después se separa de ellos y busca abrir su propia empresa, pero no tiene el éxito de la empresa Selectasine, quienes tuvieron un enorme éxito.

Martínez Vela (2013:87) comenta que:
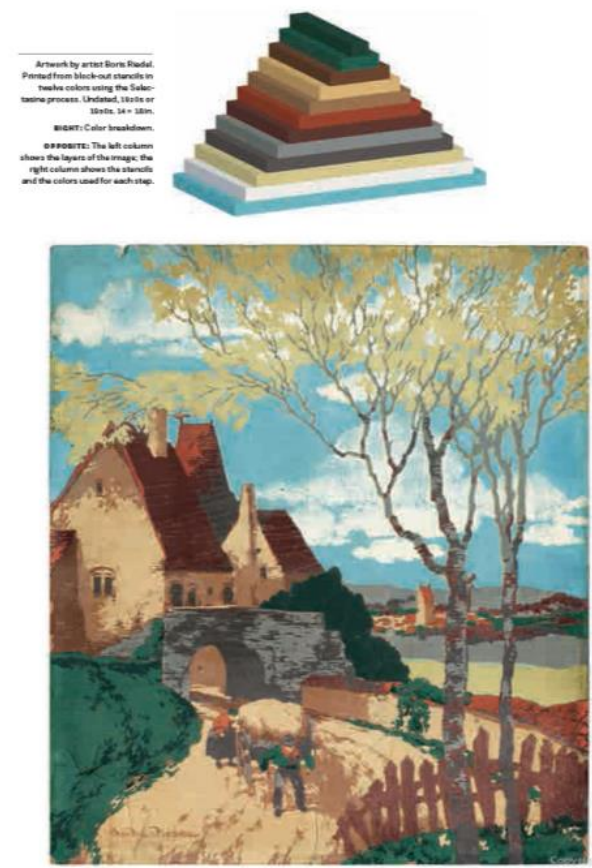
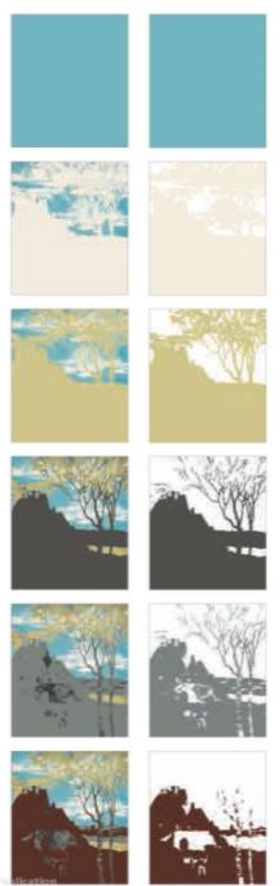
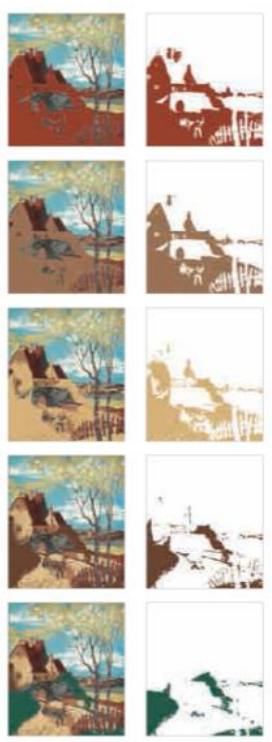

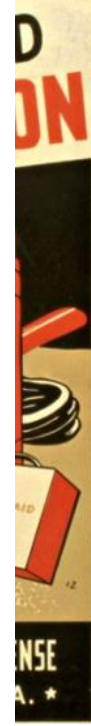

dial.

Figura 25: Ejemplo del método selectasine. Representación esquemática de la composición del color

El método Selectasine consistía en un proceso de impresión por reducción; se partía de una sola pantalla con la que se imprimía en primer lugar un color que ocupaba la mayor superficie del diseño. A continuación, se iba bloqueando gradualmente áreas sobre la misma pantalla y se iban imprimiendo los siguientes colores, cada vez con una superficie menor, superponiéndolos a los anteriores.

Además, Martínez vela (2013:92) comenta que:

En 1928 la empresa alemana Marabu produjo la pintura oleosa "Pantachrom", un producto que, aunque originalmente fue desarrollado para aplicaciones sobre cristal, se usó experimentalmente en serigrafía», esto significó un enorme paso hacia adelante, y desde entonces se empezaron a fabricar tintas y otros productos específicos para la serigrafía.

La época de la Segunda Guerra Mundial fue un periodo donde la serigrafía encontró mayor acogida y aprovechamiento, pues el ejército de los Estados Unidos volvió a retomar la serigrafía como un arma publicitaria para su propio beneficio, como menciona Martínez Vela (2013:93) utilizándola de manera masificada para: «la impresión de carteles, embalajes, insignias, armamentos, suministros médicos, e incluso mapas con tintas fosforescentes que usaron en vuelos nocturnos. " Se convierte en una herramienta para la manipulación de masas efectiva, rápida y de bajo costo. 
Pero al mismo tiempo, Estados Unidos se encuentra en una época de crisis ante la Gran Depresión, estando casi al borde del colapso, enfrentándose ante una deplorable situación social y económica, que afecta enormemente a la población estadounidense, pero que se vuelve un estímulo creativo para los artistas norteamericanos, quienes también se veían motivados a utilizar esta técnica por lo económica que resultaba, y como dice Dawson (1982:124) «les permitía llegar a un amplio público que deseaba comprar grabados originales, pero baratos»

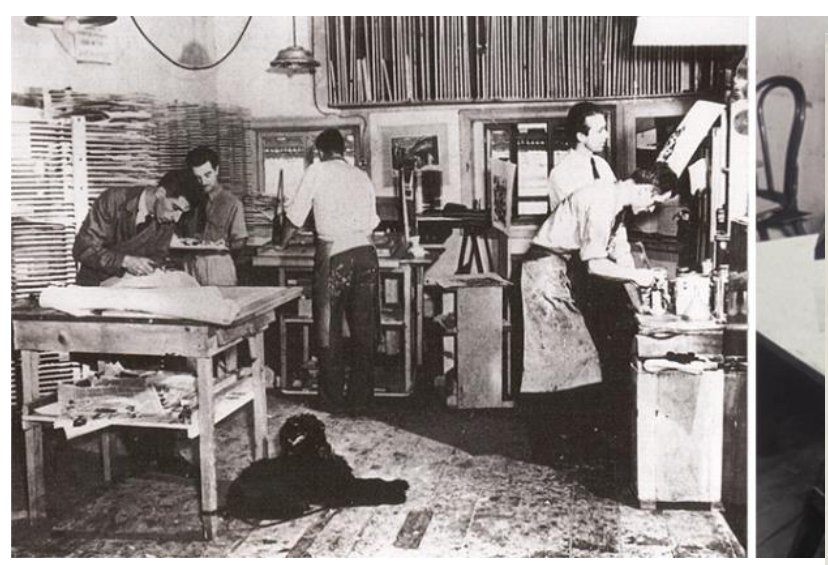

Figura 27: Anthony Velonis en su estudio de

Uno de los artistas más importantes, y que se vuelve un punto de inflexión en la historia de la serigrafía, es Anthony Velonis, quien, nos comenta Martínez Vela (2013:93) que: «contribuyó sustancialmente a abrir las puertas de la serigrafía a los artistas a través de la unidad de serigrafía del Federal Art Proyect (FAP/WPA) de Nueva York, un proyecto desarrollado para ocupar a cientos de artistas durante la gran depresión.».

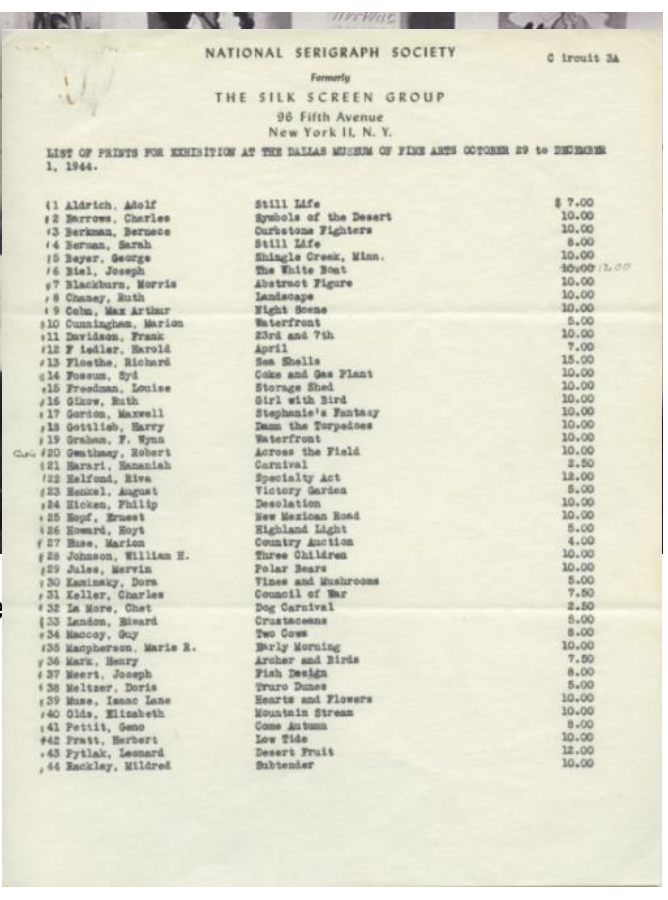

Figura 28: Lista de verificación de la exposición, "National Serigraph Exhibition", del 29 de octubre al 1 de diciembre de 1944, celebrada en el Museo de Bellas Artes de Dallas.

Gracias a su aportación, no solo ayudó a muchos jóvenes artistas a conseguir un empleo para sobrevivir a la gran depresión, si no que generó una enorme comunicación entre ellos, creando así una enorme contribución al legado artístico del país, como Hainke (1989:314) comenta en su libro: «este es el punto de partida directo no solo de la serigrafía americana, si no de la mundial.» 
Figura 29: Recorte de la página 30 del periódico The New York Times que anuncia la vigésima exposición anual en el Museo de Riverside, 310 Riverside Drive, la National Serigraph Society. 7 de mayo de 1959.

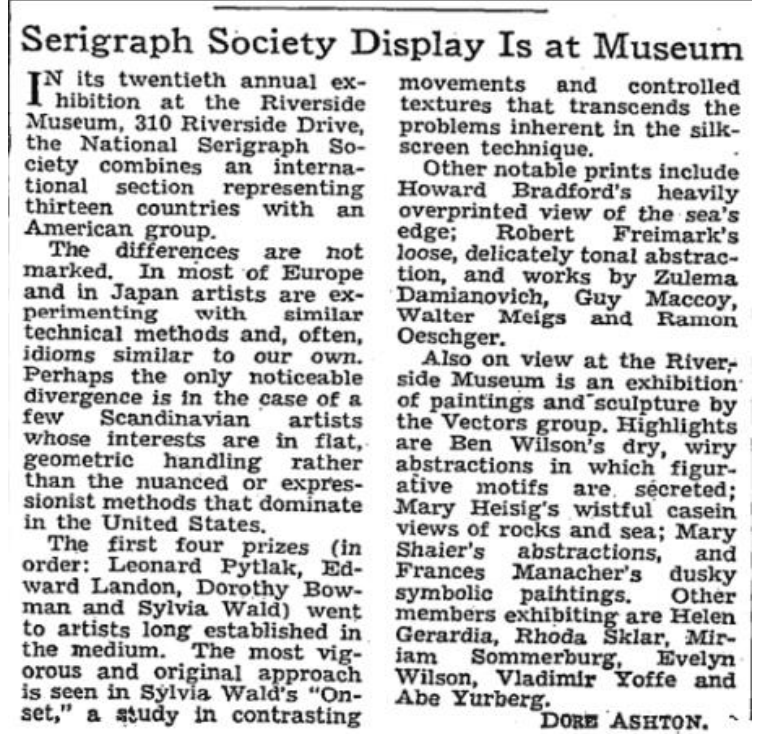

Gracias a esta organización, los artistas descubrieron que podían utilizar la técnica como un medio de expresión artística, desligándose del uso comercial que se le había dado hasta entonces, y de esto Martínez Vela (2013:172) comenta que: «Velonis defendía que la serigrafía debía tener su lenguaje propio y expresarse con sus propios recursos, con sus limitaciones y características peculiares, sin intentar imitar los resultados de otros medios gráficos 0 pictóricos.» La serigrafía comienza a ser utilizada como medio autónomo de expresión y comienzan a desarrollarse métodos y procedimientos adecuados a sus exigencias.

También, Hainke (1989:314) nos comenta que «la serigrafía es el primer regalo de arte de EE.UU. a Europa.» $A$ partir de este momento, la expansión de la técnica serigráfica se da de manera súbita y paulatina; los artistas americanos utilizaban la serigrafía como un medio para expresar su visión personal sobre la situación de crisis en la que se desenvolvían, los sentimientos de desgracia ante la severa recesión económica del país, y se buscó crear un nuevo arte sobre la identidad nacional. El número de artistas que utilizaban esta técnica crecía a pasos agigantados.

En el año 1939, doce artistas plásticos se unen (algunos de los cuales habían trabajado con Velonis con anterioridad) y se crea el grupo llamado Silk Screen Group; Esta asociación cambio su nombre en 1945, por Nacional Serigraph Society, y montaron este mismo año una galería en Nueva York que existió hasta 1962, cuando cambió el nombre por Print Club.

Esta asociación de artistas tenía como objetivo dar a conocer los procesos serigráficos, y darle un lugar importante en el arte, y demostrar que era una técnica artística independiente, con la que era posible crear obras artísticas que pudieran estar expuestas en un museo; Martínez Vela (2013:176) nos comenta el nombre de algunos de estos artistas a continuación: «Sara Berman, Judson Briggs, Max Arthur Cohn, Graham Wynn, Ernest Hopf, Edward Landon, Harry Shokler o Harry Sternberg».

Las obras producidas por estos artistas obtienen un enorme éxito a nivel tanto nacional como internacional, reciben una respuesta muy favorable de los críticos de arte, por lo que sus obras recorren un gran recorrido internacional y empiezan a formar parte de colecciones de museos importantes, como el MOMA de Nueva York.

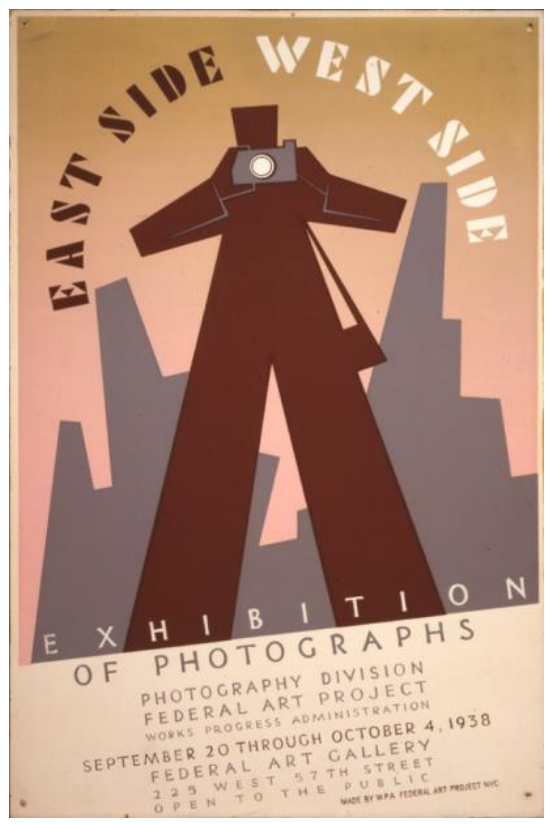

Figura 30: East Side West Side Exhibición de fotografías por Anthony Velonis, Proyecto de arte federal de la ciudad de Nueva York, WPA, 1938. 


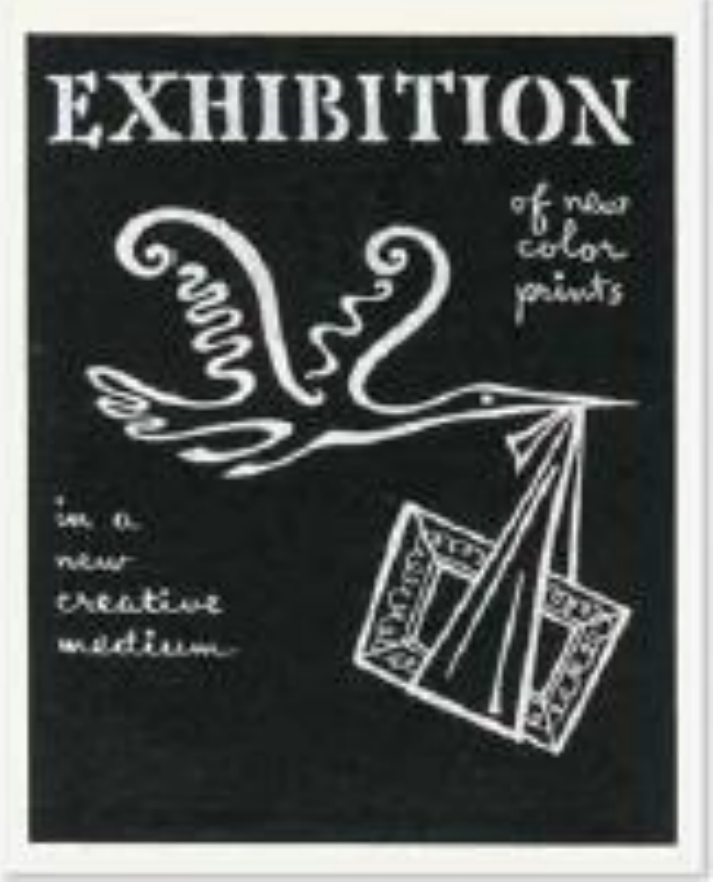

Figura 31: Portada del catálogo de la exposición en la Weyhe Gallery. Marzo de 1940
En esta época, los artistas de la serigrafía, en esa búsqueda constante de entrar en el mundo del arte y hacerse de un espacio en el mercado artístico, querían que las personas diferenciaran entre, lo que era el proceso de estampación con mallas con fines industriales y comerciales masificados, y las obras que realizaban que solo tenían un fin artístico y expresivo, por lo que, en el año 1940 acuden a Carl Zigrosser, que según Martínez Vela (2013:182) era «director de Weyhe Gallery de Nueva York y posteriormente conservador de estampas del Philadelphia Museum of Arts», quien considera que el problema estaba en que se utilizaba un mismo término para calificar tanto al proceso artístico como el industrial, así que utiliza el término serigraph para referirse a las obras artísticas, el cual emplea por primera vez en el texto del catálogo de la exposición celebrada en la Weyhe Gallery en marzo de 1940.

Entonces, el conjunto de todos estos sucesos, como comenta Martínez Vela (2013:81) se convierten en «los primeros pasos para que tanto los críticos como el público y los coleccionistas empezaran a reconocer que se hallaban ante una nueva forma de expresión artística equiparable a las ya conocidas.»

En los años cincuenta la serigrafía amplía su campo de aplicación en la industria y experimenta una rápida evolución, se empiezan a utilizar diferentes tipos de soportes a los convencionales. Durante este periodo también hay una enorme discusión sobre los inconvenientes que tiene la técnica; la originalidad, y como comenta Hainke (1989:317) «el abuso de ella como medio de reproducción, que posibilita las tiradas en masa. En 1951, Fernand Léger había hecho imprimir 1000 ejemplares de un trabajo y con ello había dinamitado la idea habitual de "original".»

Aunque se buscó en gran medida que la serigrafía fuera tomada enserio como técnica artística, en esta época las personas todavía no diferenciaban entre la técnica artística y el proceso comercial, por lo que sufrió un pequeño declive entre los artistas estadounidenses, a pesar de los esfuerzos tanto de Velonis como Zigrosser por reivindicar a la serigrafía.

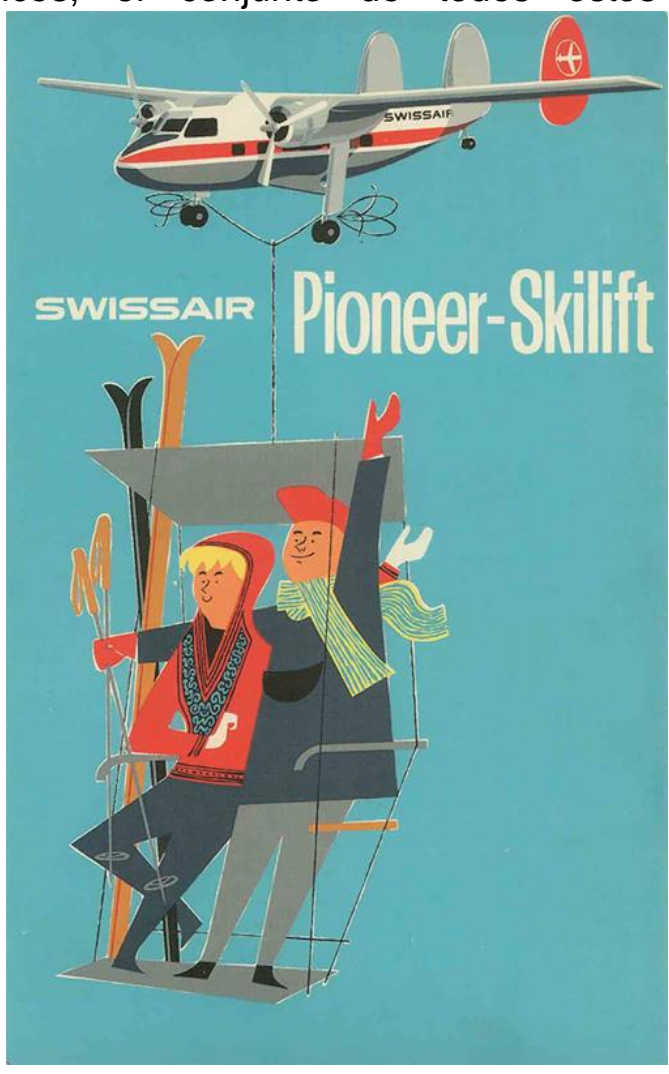

Figura 32: Cartel Swissair impreso en serigrafía (10 colores) en la década de 1950. 
Muy por el contrario, en Europa la serigrafía alcanza un gran desarrollo, ya que en varios países de este continente se realizan exposiciones de serígrafos americanos, quienes, según Martínez Vela (2013:189) «pretendían ensalzar la técnica serigráfica como un producto genuinamente americano»

Los países donde principalmente se desarrolla la serigrafía en Europa serían, el Reino Unido, Francia y Alemania, donde trabajan importantes artistas.

En la década de los años sesenta, la serigrafía vuelve a resurgir en los Estados Unidos, ya que durante la época comprendida entre 1935-1960, los artistas de esa época, como comenta Martínez Vela (2013:194):

evitaron cualquier "contaminación" de lo comercial despreciando el uso de la fotografía, de las imágenes populares, de las técnicas comerciales, o una participación reducida en el proceso creativo, pues pensaban que la obra de arte tenía que ser realizada totalmente por la mano del artista.

A principios de la década de los años sesenta, los tiempos de declive de la serigrafía en Estados Unidos dan un vuelco, y resurge con una enorme fuerza gracias al surgimiento del Pop Art, que era un reflejo del espíritu de la época en el país, caracterizada por los nuevos hábitos y conductas consumistas, el bombardeo de información por los medios masivos de comunicación, la euforia por las nuevas tecnologías, y el culto a las estrellas del momento; los artistas en estos momentos «se sienten más próximos a las imágenes de la cultura popular, a publicidad y los medios de comunicación, están más interesados por la fabricación en serie que por el trabajo artesanal y la serigrafía se adapta perfectamente a su discurso plástico». (Martínez Vela, 2013:194)

Los artistas americanos se dan cuenta de las grandes ventajas de la serigrafía, al ser una técnica de bajo costo, y que genera obras de manera muy rápida y eficiente que tiene muchas posibilidades creativas, y cambian la mentalidad de los años anteriores, Se dan cuenta que es posible crear obras de gran interés con estos colores planos y brillantes, además de que se adaptan a los nuevos tiempos que les rodean y toman

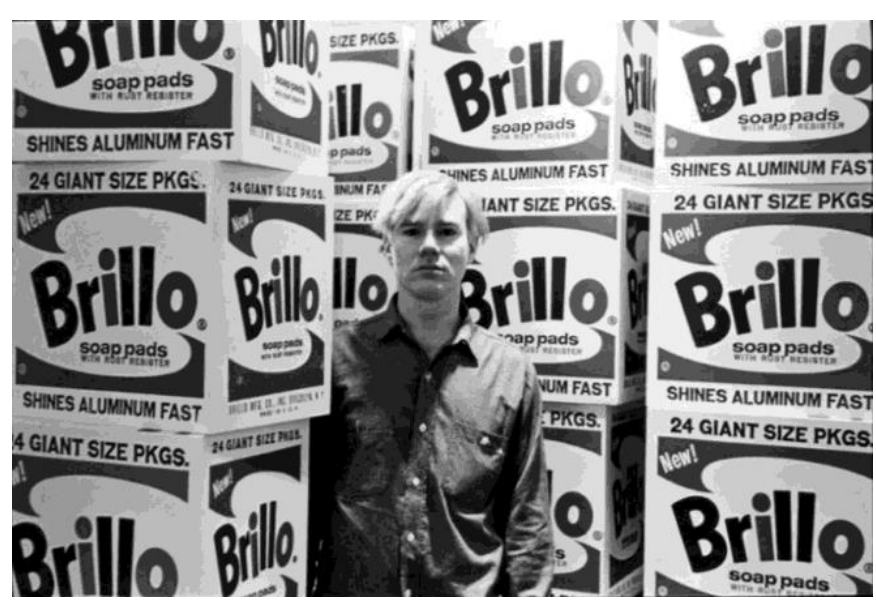

Figura 33: El artista pop estadounidense Andy Warhol (1928 1987) se encuentra en medio de sus imponentes esculturas de cajas de Brillo en la Galería Stable (33 East 74th Street), Nueva York, Nueva York, 21 de abril de 1964. mercado, del selecto grupo de las
litografía no se había ampliado». como referencia la imágenes de los medios de comunicación, Martínez Vela (2013:194), comenta que los americanos ya no consideran el arte como «algo sublime, si no como algo más cercano, desprovisto de significados trascendentes y subjetividades».

Gracias a la serigrafía el Pop Art obtiene un éxito rotundo, y de la misma manera, gracias al Pop Art, y a las grandes aportaciones de los artistas de esta vanguardia, es que la serigrafía es finalmente considerada una técnica artística, y empieza a formar parte, según Martínez Vela (2013:195) «con el reconocimiento de los críticos, galeristas, artistas y el propio mercado, del selecto grupo de las técnicas gráficas que desde la incorporación de la 
Las obras de Andy Warhol, que tuvieron un enorme éxito, situaron a la serigrafía como técnica gráfica en el lugar importante que desde siempre se había buscado. En 1964, Warhol expone en la galería de Nueva York llamada Stable, una galería que tenía la reputación de exponer la obra de artistas emergentes que eran muy controvertidos y polémicos de esta época. Realiza una exposición individual, donde presenta una serie de obras que representaban objetos cotidianos. Realiza estas obras con serigrafía y en mayor tamaño, colocando algunas de ellas sobre estantes como si estuvieran en los pasillos de un súper mercado, lo que significo, no solo una gran controversia, sino también una revolución en el mundo del arte, ya que ponía en cuestión el concepto de originalidad, que para él ya era algo anticuado.

\section{5.- El Kelpra Studio en Londres}

Al mismo tiempo, en Londres se ve un gran avance en paralelo en los procesos serigráficos, gracias a la aportaciones de grandes artistas de la serigrafía, de los cuales es que se considera el más sobresaliente es Chris Prater, quien en el año 1957, inicia un negocio de serigrafía con su esposa Rose, al que le ponen el nombre de Kelpra Studio, que fue muy importante para el desarrollo de la serigrafía artística; Martínez Vela (2013:195) nos comenta que:

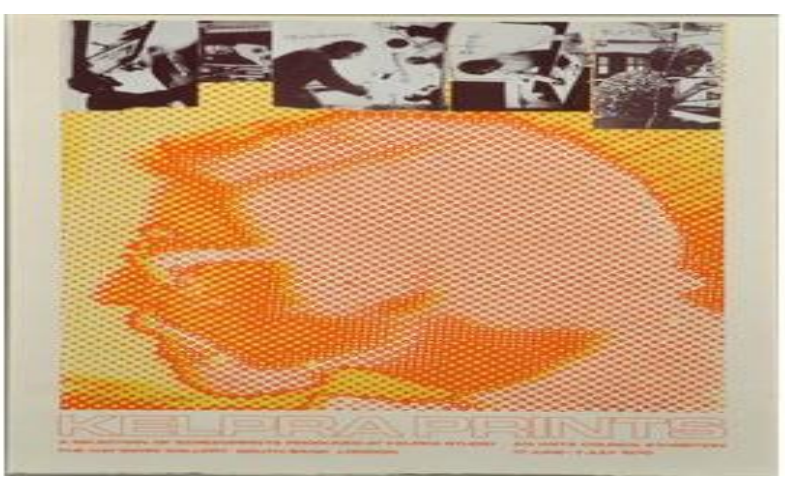

Figura 34: iUna impresión de pantalla de Kelpra Studio, firmada a lápiz por Joe Tilson y Christopher Prater, preparada para la Exposición del Consejo de Arte de

Sus primeros trabajos fueron comerciales, pero en 1959 conoce a Gordon House, un diseñador gráfico y pintor, que le encargó el primer trabajo artístico del taller Kelpra. El éxito que obtuvo atrajo a artistas como Richard Hamilton, Eduardo Paolozzi, Joe Tilson y Richard Smith; le piden al Institute of conterporary Arts que le patrocine una carpeta de serigrafías, y la carpeta se publicó en 1964 e incluía a 24 artistas. Este fue el punto de partida para muchos de ellos en una fecunda trayectoria como artistas gráficos.

\section{2.- Tendencias actuales}

El desarrollo de los procesos de impresión de las artes gráficas a partir del último cuarto del siglo XX y los primeros años del siglo XXI, se genera de manera proporcional en los procesos serigráficos; los artistas se ven alentados a utilizar en su producción artística los nuevos procesos técnicos, materiales y soportes, y se van difuminando los limites habidos aprovechando los avances de las nuevas tecnologías, facilitando la producción serigráfica ante los proceso tradicionales pero sin realmente remplazarla, solo mejorando el procedimiento a favor del artista contemporáneo, como comentan Sanders y Millers:

Las nuevas tecnologías han cooptado rápidamente para la estampación artística, al mismo tiempo, algunos artistas han continuado explorando el potencial sin explotar de métodos más tradicionales, ya sea imprimiendo en superficies distintas al papel, trabajando en una escala sin precedentes o simplemente trabajando de una manera que expanda las definiciones de 'imprimir". El auge de los nuevos medios, visto por algunos como una amenaza para el futuro del grabado, simplemente ha ampliado las opciones disponibles.

En el siglo XXI el campo de la creación artística se convierte en un espacio para el desarrollo de proyectos, los artistas demuestran un creciente interés en la innovación 
de los procesos técnicos, y también de la investigación en el arte para beneficio de un discurso que se el esqueleto que fundamente toda creación artística, según Saunders y Miller:

Muchos artistas mezclan medios y formas de manera regular y libre, tomando las decisiones que mejor sirven sus conceptos y propósitos. Las actividades varían desde proyectos espectaculares realizados con presupuestos enormes y valores de producción extraordinarios hasta esfuerzos modestos que enfatizan procesos, y experiencias efímeras. La noción de influencias también ha cambiado con los cambios en las comunicaciones y la tecnología; Cada lugar en todo el mundo tiene artistas que responden a geografías e historias locales, así como a la influencia de la cultura visual global.

En la actualidad hay una gran cantidad de artistas visuales que se inclinan por utilizar la serigrafía como medio para la creación de su obra artística, hay un enorme interés en la investigación de esta técnica, no solo para el mejoramiento de los procesos técnicos y matéricos, también se realiza una enorme experimentación con diferentes materiales y técnicas para alcanzar nuevos métodos.

Nos encontramos en un momento donde las posibilidades son infinitas, para el artista las posibilidades son infinitas, y los artistas contemporáneos tienen la oportunidad de seguir explotando todos los procedimientos, desde los más tradicionales a los procesos de estampación más novedosos de la actualidad, logrando realizar estampaciones con una cantidad de detalle sin precedentes.

\section{Referencias}

Libros

Cossu, M., \& Dalquié, C. (2015). La Serigrafía. Un completo manual de herramientas, técnicas y ejemplos de artistas internacionales. (V. Pradilla, Ed.) Barcelona, España: Gustavo Gili.

Dawson, J. (1982). Guía completa de grabado e impresión: técnicas y materiales. (L. Wildhide, Ed., \& J. M. Ibeas, Trad.) Madrid, España: Hermann Blume.

Faine, B. (1991). Nueva guía de serigrafía (Primera ed.). (P. Selígrnan, Ed., T. Huerta, \& M. J. Schwarz, Trads.) D.F., México: Diana.

Hainke, W. (1989). Serigrafía - técnica, práctica, historia. España: Ediciones La Isla.

Martínez Vela, M. (2013). La Serigrafía. de la pantalla de seda a la estampa. Sevilla: Point de lunettes.

Martínez Vela, M. (2012). La serigrafía artística. proceso evolutivo, difusión y enseñanza de una técnica gráfica aplicada a la creación plástica. Técnicas menos agresivas para el artista 0 el impresor. (Tesis Doctoral) Universidad de Granada. Granada, España.

Muñoz del Almo, Á. (Junio de 2013). La mano, la huella y el acto de estampar. HipoTesis.

Ross Nielsen, G. (1965). Serigrafía industrial y en las artes gráficas. Barcelona: Las ediciones de arte.

\section{Documentos de internet}

Crespo, C. (1986). La reprografía en los archivos. Recuperado el 12 de noviembre de 2018, de Dialnet: https://dialnet.unirioja.es/ejemplar/85987

Google Arts \& Culture. (s.f.). Ise Katagami Stencil. Recuperado el 26 de octubre de 2018, de https://artsandculture.google.com/exhibit/DwJS1XVSx5phKgç

Saunders, G., \& Miles, R. (s.f.). Printmaking in the 21 st century. Recuperado el 05 de noviembre de 2018, de Victoria and Albert Museum The world's leading museum of art and design: http://www.vam.ac.uk/content/articles/p/prints-21st-century/

South Florida Art Conservation. (25 de octubre de 2012). Pochoir: Technique and Conservation. Recuperado el 05 de diciembre de 2018, de http://sflac.net/uncategorized/pochoir-techniqueand-conservation/

The Editors of Encyclopaedia Britannica. (06 de junio de 2008). Stenciling. Art. Recuperado el 06 de diciembre de 2018, de https://www.britannica.com/art/stenciling\#ref125328

Wikipedia, the free encyclopedia. (12 de mayo de 2018). Mimeograph. Recuperado el 28 de octubre de 2018, de https://en.wikipedia.org/wiki/Mimeograph

Índice de imágenes

Figura 1: Martínez Vela, M. (2013). De los primeros estaridos a la serigrafía artística: esquema evolutivo. [esquema] Recuperado 
del libro: La Serigrafía. de la pantalla de seda a la estampa. Sevilla: Point de lunettes. (p. 21)

Figura 2: Cecowski M. (2005) Impresiones en la Cuevas de las Manos sobre el Río Pinturas en la provincia de Santa Cruz, Argentina. [Fotografía] Recuperado de: https://es.wikipedia.org/wiki/Cueva_de_las_Manos

Figura 3: Cueva de Maltravieso. [fotografía] (s.f) Recuperado de: http://www.turismoextremadura.com/viajar/turismo/es/explora/ Cueva-de- Maltravieso_1924203554/

Figura 4: Susuka City. (s.f) Plum and Nightingale (detail), Ise katagami. [Fotografía] Recuperado de: https://artsandculture.google.com/exhibit/DwJS1XVSx5phKg

Figura 5: Summer Kimono. [Fotografía] (s.f) Recuperado de: https://collections.lacma.org/node/211843

Figura 6: Noh Costume (Surihaku) with Water, Water Plants, and Leaves [Fotografía] (s.f.) Recuperado de https://www.metmuseum.org/art/collection/search/61198

Figura 7: Plantilla de papel perforado (Sthepenson) [Imagen] (s.f.) Recuperado del libro de Martínez Vela, M. (2013) La Serigrafía. de la pantalla de seda a la estampa. Sevilla: Point de lunettes. (p.34)

Figura 8: Law, T. (2010) dunhuang06 [Fotografía] Recuperado de: https://www.nationalgeographic.com.es/mundo-ng/grandesreportajes/las-cuevas-de-los-mil-budas_2490/6

Figura 9: Perez Gonzalez A. (2006). Baraja Carlos IV by Félix Solesio, 1800. [Fotografía] Reuperado de http://www.wopc.co.uk/spain/macharaviaya/carlos-iv

Figura 10: Section of Stenciled Plaster Wall and Lating [Fotografía] (s.f.) Recuperado de https://americanart.si.edu/artwork/section-stenciled-plasterwall-and-lating-7725

Figura 11: Stencil. Patente de Bernard Lowenson [imagen] (s.f) Recuperado de Martínez Vela, M. (2012).La Serigrafía artística. Proceso evolutivo, difusión y enseñanza de una técnica gráfica aplicada a la creación plástica. Técnicas menos agresivas para el artista o el impresor. (tesis doctoral) Universidad de Granada. Granada, España. (p.38)

Figura 12: Bibliothèque Forney (13 de enero del 2017) Traité d' \#enluminure d'art au \#pochoir, 1925 [Publicación de Twitter] Recuperado https://twitter.com/bibforney/status/81991014671332966

Figura 13: [Fotografía del proceso para generar una obra con la técnica de Pochoir] (s.f) Recuperado de: https://pochoirworld.com/

Figura 14: Henri Matisse. The Codomas (Les Codomas) from Jazz. 1947 [Fotografía] (s.f.) Recuperado de: https://www.moma.org/collection/works/105389?association= portfolios\&locale=es\&page=1\&parent_id $=66170 \&$ sov_referrer =association

Figura 15: Koehne A. (2006) Mimeograph [llustración] Recuperado de: https://commons.wikimedia.org/wiki/File:Mimeograph.svg
Figura 16: San Francisco Public Library (2010) Image from page 51 of "Coast review" (1871) [Fotografía] Recuperado de: https://archive.org/details/coastreview141879sanf/page/n5

Figura 17: Electric pen outfit at Greenfield Village [Fotografía] (s.f) Recuperado de: http://electricpen.org/

Figura 18: Gestetner's Neo-Cyclostyle Duplicating Machine, c. 1890 [Fotografía] (s.f) Recuperado https://www.invaluable.co.uk/auction-lot/gestetner-s-neocyclostyle-duplicating-machine-c-58-c-9a84d42bd8\#

Figura 19: Heritage Auctions. Edison Mimeograph Machine (1886) [Fotografía] (s.f) Recuperado de: https://comics.ha.com/itm/memorabilia/miscellaneous/edisonmimeograph-machine-1886-/a/7151-95101.s

Figura 20: Cédula de Patente de Samuel Simons [Fotografía] (s.f) Recuperado de: Martínez Vela, M. (2012). La serigrafía artística. proceso evolutivo, difusión y enseñanza de una técnica gráfica aplicada a la creación plástica. Técnicas menos agresivas para el artista o el impresor. (p. 58)

Figura 21: Cédula de Patente de François Schreus. [Fotografía] (s.f) Recuperado de: Martínez Vela, M. (2012). La serigrafía artística. proceso evolutivo, difusión y enseñanza de una técnica gráfica aplicada a la creación plástica. Técnicas menos agresivas para el artista o el impresor. (Tesis Doctoral) Universidad de Granada. Granada, España. (p. 60)

Figura 22: S.S. Great Northern-S.S. Northern Pacific [Fotografía] (s.f) Recuperado de: http://www.philamuseum.org/collections/permanent/268187.ht $\mathrm{ml}$

Figura 23: Annonce les premiers kits de sérigraphie en 1925. $\begin{array}{lll}\text { [Fotografía] (s.f) } & \text { Recuperado de } \\ \text { https://www.dezzig.com/histoire-secrete-de-la-serigraphie-2/ }\end{array}$

Figura 24: Edwards Owen aux commandes du Selectasine Printshop en 1916-1918 [Fotografía] (s.f) Recuperado de: https://www.dezzig.com/histoire-secrete-de-la-serigraphie-1les-pionniers/

Figura 25: Schematische Darstellung des Farbaufbaus [Fotografía] (s.f) Recuperado de http://www.silkscreenhistory.com/book_selecta_de-neu.pdf

Figura 26: Everett Collection. Este es tu aire protección RAID Obténgalo ahora [Fotografía] (s.f) Recuperado de: https://www.alamy.es/foto-la-segunda-guerra-mundial-estees-tu-aire-proteccion-raid-obtengalo-ahora-cartel-alentando-alos-civiles-a-prepararse-adecuadamente-para-ataquesaereos-mostrando-la-pala-el-hacha-extintor-linterna-botiquinde-primeros-auxilios-la-cuchara-de-arena-gafas-y-un-tuboserigrafia-en-color-ca-1942-32385138.html

Figura 27: Anthony Velonis (à droite) dans son atelier de sérigraphie. New York, 1939. [Fotografía] (s.f) Recuperado de: https://www.dezzig.com/histoire-secrete-de-la-serigraphie-2/

Figura 28: Dallas Museum of Fine Arts. Checklist for National Serigraph Exhibition [Escaner] (s.f) Recuperado de: https://texashistory.unt.edu/ark:/67531/metapth225390/ 
Figura 29: The New York Times. THURSDAY, MAY 7, 1959 [Fotografía] (s.f) Recuperado de: https://timesmachine.nytimes.com/timesmachine/1959/05/07/i ssue.html

Figura 30: East Side West Side Exhibition of Photographs par Anthony Velonis, New York City Federal Art Project, WPA, 1938. Silkscreen Prints and Photographs Division, Library of Congress [Fotografía] (s.f) Recuperado de: https://www.dezzig.com/histoire-secrete-de-la-serigraphie-2

Figura 31: Portada de los catálogos de las dos primeras exposiciones colectivas de serigrafia [Fotografía] (s.f) Recuperado de: Martínez Vela, M. (2012). La serigrafía artística. proceso evolutivo, difusión y enseñanza de una técnica gráfica aplicada a la creación plástica. Técnicas menos agresivas para el artista o el impresor. (p. 121).

Figura 32: Serico Cie Archives. Affiche Swissair imprimée en sérigraphie (10 couleurs) dans les années 1950 [Fotografía] (s.f) Recuperado de: https://www.dezzig.com/histoire-secretede-la-serigraphie-3/

Figura 33: American pop artist Andy Warhol (1928 - 1987) stands amid his towering Brillo box sculptures in the Stable Gallery (33 East 74th Street), New York, New York, April 21, 1964. [Fotografia] (s.f) Recuperado de: https://oscarenfotos.com/2016/05/14/andy-warholfotografo/warhol-brillo-boxes-at-stable-gallery/

Figura 34: A kelpra studio screen print, signed in pencil by joe tilson and christopher prater [Fotografía] (s.f) Recuperado de: https://www.the-saleroom.com/en-gb/auction-catalogues/tringmarket-auctions/catalogue-id-stri10015/lot-1b3f6111-59f64eca-a8f0-a46101140648 